\title{
Contagion Channels between Real Estate AND FinANCIAL MaRKETS*
}

\author{
Martin Hoeslif and Kustrim Reka用
}

January 23, 2013

\begin{abstract}
The recent crisis has demonstrated the close linkages between various asset classes within a country as well as the association between assets internationally. The aim of this research is to provide for a better understanding of some of these linkages by conducting an empirical investigation of the channels underlying the risk of contagion between real estate and financial markets in the United States. We test for three financial mechanisms driving contagion: Information correlation, liquidity correlation, and portfolio rebalancing. A behavioral dimension in the crisis propagation is also examined by considering investor sentiment and panic risk in our analyses. A methodology based on quantile regressions and copulas is utilized for carrying out those tests. We find that contagion prevails between real estate and financial markets and that this is driven by behavioral and liquidity mechanisms. The correlated information and portfolio rebalancing hypotheses are strongly rejected. The results of this research should prove useful to investors seeking to hedge against market crashes as well as to policy makers who aim to mitigate such stressful episodes.
\end{abstract}

JEL Classification: G01; G12; G02; G14

Keywords: Real Estate; Contagion Channels; Sentiment; Liquidity; Financial Markets

${ }^{*}$ The authors have benefited from discussions with Anjeza Kadilli, Jongsub Lee, David Ling, William Maher, Andy Naranjo and David Watkins. Financial support by the Real Estate Research Institute (RERI) is gratefully acknowledged.

${ }^{\dagger}$ University of Geneva (HEC and SFI), 40 boulevard du Pont-d'Arve, CH-1211 Geneva 4, Switzerland, University of Aberdeen (Business School), Edward Wright Building, Aberdeen AB24 3QY, Scotland, U.K. and Bordeaux Ecole de Management, F-33405 Talence Cedex, France or martin.hoesli@unige.ch (corresponding author)

${ }^{\ddagger}$ University of Geneva (HEC), 40 boulevard du Pont-d'Arve, CH-1211 Geneva 4, Switzerland or kustrim.reka@unige.ch 


\section{Executive Summary}

The connections between various assets within a country as well as the linkages between international markets have received considerable attention in the academic literature. This topic is of importance since it has direct implications for portfolio diversification and countries' financial stability. Financial contagion is a crucial issue related to this topic and its consequences on a country's economy may be tremendous, as illustrated by the recent financial crisis. Indeed, several markets suffered catastrophic losses initially triggered by large defaults by subprime borrowers in the U.S. mortgage markets. Loosely speaking, contagion can be defined as a rapid shock spillover that increases cross-market linkages. Examining the determinants of those linkages is crucial in order to fully understand this phenomenon. Despite the role played by real estate in the recent financial crisis and its importance in the economy, there is no study in the literature that addresses the issues of the contagion channels involving this market. This paper aims to fill this gap. More precisely, we use the interdependences between the U.S. real estate and equity markets as our testing ground. Thus, we analyze the dynamics of financial contagion within a cross-asset framework (domestic contagion). Real estate investments trust data have been selected to proxy for real estate returns. As for financial markets, three sub-indices of equity markets (i.e. small cap, large cap and commercial bank stocks) are used for the analyses.

In this study, we seek to answer two questions. First, defining contagion as return comovements that cannot be explained by economic fundamentals, is there contagion between real estate and financial markets? Second, what are the mechanisms underlying contagion in this context? We test for three financial mechanisms driving contagion: Information correlation, liquidity correlation, and portfolio rebalancing. The first channel hypothesizes that the economic news related to a shock to one market are directly relevant for the prices and/or cash flows in other markets due to information asymmetries. In the second channel, credit accessibility and the tight relations between markets' liquidity are supposed to strengthen the links between markets. Finally, the third channel suggests that contagion emerges when agents reallocate their portfolio in response to large losses in one or several markets. A behavioral dimension in the crisis propagation is also examined by taking into account investor sentiment and panic risk in our analysis. Here, we expect that low sentiment (i.e., pessimism) increases the likelihood of contagion. Our empirical

investigation relies on the use of copulas and quantile regressions. This methodolog- 
ical approach allows us to analyze the tail distributions of the return series, which is of importance in our framework as contagion is characterized by extreme events.

Our empirical analyses provide us with the following results. First, we find striking evidence of contagion between real estate and stock markets over the 1999-2011 period. Second, information correlation and portfolio rebalancing appear to have no role in this contagion. On the other hand, liquidity dynamics and credit availability are found to be significant factors. Finally, we also document that investor sentiment significantly contributes to increasing the risk of contagion between real estate and equity markets. Stated differently, pessimism amongst market participants is found to be a major factor in explaining excess comovements in our context. This provides evidence for the increased behavioral biases during market downturns.

These findings have several policy and practical implications. First, risk management and policies based on standard asset pricing models that ignore the risk of contagion are misleading during stressful periods. Indeed, return comovements are greater than what is implied by economic fundamentals during extreme market conditions and diversification across stocks and real estate is not that useful during such periods. Second, policies that facilitate credit accessibility (especially during a crisis) could avoid or at least limit the magnitude of contagion. Lenders will be cautious for good reasons but government policy should suggest innovative ways of encouraging lending. Finally, a better understanding of how market frictions and investor sentiment affect comovements and markets in general would lead investors to make more appropriate decisions as regards risk diversification. Also, policies that ignore the psychological factors in stressful times may fail to offset the widespread impact of a crisis. In other words, policies that only try to regulate institutional behavior in order to diminish the impact of a crisis are likely to be sub-optimal. 


\section{Introduction}

The extreme events that unfolded in 2007-2008 in real estate and financial markets and that remain ongoing with the current debt crisis and the threat of its propagation to many countries have strengthened the desire of researchers to better understand the mechanisms driving domestic and international financial contagion. Loosely speaking, contagion can be defined as a rapid shock spillover that increases cross-market linkages. However, no real consensus has emerged from the financial economics literature on the definition of contagion. We choose to use the definition proposed by Bekaert, Harvey and Ng (2005) that has been widely utilized in recent studies. Contagion is defined as the 'correlations over and above what might be expected by economic fundamentals'; thus, 'contagion' through common shocks is ruled out by construction. This point is paramount as we might mistakenly conclude that there is evidence of contagion by observing an increase in the correlation between two markets, while this increase (often noted in periods of crisis) might only be the consequence of the exposure of those two markets to common risk factors. Therefore, the first step in any contagion analysis is to set up a pricing model that controls for shared economic risk factors. The purpose of this research is to examine the determinants of excess comovements in a domestic market (cross-asset contagion), by focusing on contagion between real estate and financial markets in the U.S.

The literature on contagion has largely focused on markets such as stocks, currencies, and more recently hedge funds (e.g., Bae, Karolyi and Stulz 2003; Eichengreen, Rose and Wyplosz 1996; Boyson, Stahel and Stulz 2010) and has found strong evidence of contagion during various crisis periods. The literature disentangling contagion issues concerning real estate markets is more limited. Kallberg, Liu and Pasquariello (2002) and Gerlach, Wilson and Zurbruegg (2006) are among the few papers that have studied contagion on such markets. Their focus is on the Asian flu crisis of 1997. More recent studies by Fry, Martin and Tang (2010) and Hoesli and Reka (forthcoming) test for financial contagion in securitized real estate markets during the 2007-2008 crisis. In general, those studies confirm the existence of contagion involving real estate markets. Therefore, the empirical literature on contagion has demonstrated that this phenomenon does exist both in financial and real estate markets.

Provided that contagion appears to prevail on many markets, a natural stream of research would be therefore the analysis of the channels underlying the shock 
transmissions across markets. This topic is important for investors seeking to hedge against market downturns and policy makers who aim to limit the consequences of such stressful periods. An in-depth understanding of the mechanisms driving contagion will help to make more appropriate decisions and provide for more targeted interventions. To the best of our knowledge, no research has been carried out to examine the channels of contagion involving both real estate and financial markets. We believe that it is important to fill such a gap given the role played by real estate in the recent financial crisis and its importance in the economy.

The existing literature has recognized at least three possible 'theories' of contagion, i.e., through financial linkages, trade links, and herding behavior (Kaminsky, Reinhardt and Végh 2003). The financial linkages theory stipulates that contagion might occur through three mechanisms: Information correlation, liquidity correlation, and portfolio rebalancing. The information correlation channel (King and Wadhwani 1990) is based on the price discovery process, which assumes immediate price effects in the markets affected by a financial collapse elsewhere. The model of King and Wadhwani (1990) shows that rational agents, by inferring information from price changes in some markets, can affect other markets, while the theoretical underpinning for the liquidity correlation channel investigation is provided by Brunnermeier and Pedersen (2009). The authors explain how liquidity spirals (funding liquidity and asset liquidity issues self-reinforcing) could emerge and explain a contagion phenomenon. The portfolio rebalancing channel suggests that contagion emerges when agents reallocate their portfolio in response to large losses in one or several markets (Kodres and Pritsker 2002). The first focus of this paper is on financial linkages explaining the contagion phenomenon.

As we study contagion across various asset classes in one country, the trade links theory cannot play any role in the propagation of shocks. In contrast, the third theory, i.e., the herding behavior theory (correlated trading activities across agents), may influence our findings. This stream of investigation constitutes the starting point for the second focus of our study which is to evaluate the importance of a behavioral dimension in our setup. This is in the wake of the growing behavioral economics literature that points to the role played by noise traders and investor sentiment in the price formation and return comovements (Brown and Cliff 2005; Baker and Wurgler 2006, 2007; Kumar and Lee 2006). Initially, we control for any such herding behavior by including an investor sentiment variable in our analysis. This is in the spirit of the sentiment-based comovement theory proposed by Barberis, Shleifer and Wurgler (2005) who show that sentiment may lead to return 
comovements going beyond what is expected by fundamentals. In a second step, the causal connection between the investor sentiment in stressful periods and the intensity of contagion, which may be considered as a potential crisis propagation channel (i.e., a panic risk effect), is examined. By doing so, we provide new insights to the theory developed by Barberis, Shleifer and Wurgler (2005) as we apply their theory to a particular state of the economy (i.e., a state with high uncertainty and depressed asset prices) where investors' risk aversion has increased considerably. We call this type of contagion sentiment-induced contagion. This channel is consistent with herding behavior, but we go further and bring some new insights to this theory by focusing on panics (low sentiment across investors) ${ }^{1}$

The contagion dynamics between the U.S. commercial real estate market and the domestic stock market are analyzed. There are two clear examples, namely the Asian crisis ${ }^{2}$ and the subprime crisis, showing the contribution of real estate markets in triggering financial instability; those examples highlight the importance of addressing this research question. At an estimated value of 6.6 trillion as of $2011^{3}$, commercial real estate makes up a significant percentage of U.S. wealth (about one half of stock market capitalization) which further supports our work. Using real estate data is also motivated by the theory of Brunnermeier and Pedersen (2009) who stress the higher risk of contagion when a trader is particularly leveraged in an illiquid market. The use of credit to a large extent and the illiquidity are well documented characteristics of real estate markets. Therefore, real estate markets offer an interesting laboratory for testing the theoretical predictions of Brunnermeier and Pedersen (2009). Real estate investments trust (REIT) data have been selected to proxy for real estate returns as this type of data has the characteristics needed to test contagion (e.g. the availability of high frequency data) and does not suffer from the drawbacks of private real estate benchmarks (smoothing or unsufficient number of transactions). REIT data further offer the advantage of yielding leveraged real estate returns. As for the financial markets, three sub-indices of equity markets (i.e. small cap, large cap and commercial bank stocks) are used for the analyses.

This paper contributes to the existing literature in several ways. First, this is the first study that examines the contagion mechanisms involving real estate markets.

\footnotetext{
${ }^{1}$ As an additional analysis, we also examine how these channels could explain the excess return comovements in good times, that is, when markets exhibit extreme positive returns. This analysis allows us to assess the potential asymmetric effects of the factors underlying contagion.

${ }^{2}$ For a paper supporting the importance of real estate in the Asian crash of 1997, see Quigley (2001).

${ }^{3}$ European Public Real Estate Association (EPRA), Monthly Statistical Bulletin of December 2012.
} 
By considering real estate markets and their unique characteristics, new insights are provided to the financial contagion and asset pricing literature which generally restricts itself to the more traditional asset classes. Also, the analysis is not limited to one contagion channel, but rather to several channels. By confronting various channels we are able to assess whether some of them occur simultaneously and whether some do not play any role. Finally, this is the first study challenging directly the financial mechanisms of contagion by testing the contribution of a behavioral dimension.

Our study yields a number of interesting results. First, we find striking evidence of contagion between real estate and financial markets over the 1999-2011 period. Second, we document that liquidity dynamics (i.e., funding liquidity and commonality in liquidity) can help explain contagion, as predicted by Brunnermeier and Pedersen (2009). On the other hand, no evidence of portfolio rebalancing or correlated information between markets during stressful times is found to underlie contagion. Finally, our results are also consistent with a sentiment-induced contagion mechanism in the spirit of 'noise trader' theories. Indeed, we document that panics have a major contribution in driving contagion between real estate and equity markets. This provides evidence for the increased behavioral biases during market downturns.

The paper is structured as follows. We first present the theoretical background, before reviewing the extant empirical literature. The next section focuses on our models and empirical design. The data are discussed next. We then turn to a discussion of our results, before concluding the paper in a final section.

\section{Theoretical Background}

The first channel of contagion, i.e. the information correlation channel, relies on the rational expectations model of King and Wadhwani (1990). It postulates that agents do not have access to the same information (i.e., there is information asymmetry) and that rational uninformed traders mostly infer information from price changes that are supposed to reveal other (informed) agents' information. In such a framework, the information updates are supposed to be incorporated in prices within a short period of time. The price variations from other markets are also supposed to convey relevant information. Therefore, the economic news related to a shock to one market would be directly relevant for the prices and/or cash-flows in other markets, thus leading to contagion. In sum, contagion occurs via informational efficient markets 
(model assumption) as prices reveal all relevant information to agents. Our approach to test the information correlation channel is akin to that employed by Longstaff (2010), while being consistent with our definition of contagion. Once economic risk factors are controlled for, the speed of the price effects from one market to another is tested and assessed within a quantile regression framework (Koenker 2005).

Brunnermeier and Pedersen (2009) explain how liquidity spirals could emerge (funding liquidity and asset liquidity issues self-reinforcing) and explain a contagion phenomenon (i.e., the liquidity correlation channel). Their theory predicts that a shock to funding liquidity (tightening of credit availability by increasing margins 4 or by a decline of asset values, for instance) leads to a decrease of the market liquidity due to the fact that traders facing tighter constraints now become more reluctant to invest, especially in 'capital intensive' assets. This leads traders to lower their leverage and sell their assets at fire-sale prices (e.g., in times of crisis) which make the prices move away from their fundamental values (decline in prices). Then, and under certain conditions, this low market liquidity (and higher volatility) further tightens capital constraints because the risk of financing a trade increases which leads to higher margins. In a nutshell, both market liquidity and funding liquidity diminish and reinforce each other (liquidity spirals).

One implication of the paper by Brunnermeier and Pedersen (2009) which we are interested in is the commonality in liquidity across securitie 5 resulting from the fact that the ability to obtain funding for leveraged market participants holding various securities is impaired. Hence, a funding shock can affect the asset prices on several markets through a liquidity mechanism. Those effects are more pronounced when markets perform poorly. Examining contagion through a liquidity channel is therefore warranted. The recent credit crunch that triggered colossal losses in financial markets and its consequences on the general economy represents a good example that supports this theory (see Brunnermeier 2009). To test this mechanism, the impact of credit accessibility and liquidity commonality across assets on return excess comovements (i.e., the intensity of contagion) is assessed using a copula framework.

The cross-market reallocation model of financial contagion proposed by Kodres and Pritsker (2002) represents our theoretical motivation for the portfolio rebalancing mechanism. This mechanism is based on the idea that contagion emerges when agents readjust their portfolio in response to large losses in one market. Indeed, in-

\footnotetext{
${ }^{4} \mathrm{~A}$ margin is defined as the difference between the purchase price and the collateral value of an asset which is financed by an investor's own capital.

${ }^{5}$ For an empirical support of commonality in liquidity, see Chordia, Sarkar and Subrahmanyam (2005).
} 
vestors have an incentive to liquidate their positions in different markets in times of crisis since they have lower wealth, which pushes the prices downward. Eventually, this creates a certain comovement in the returns of assets going beyond economic fundamentals. Our approach to test this contagion channel relies on the analysis of the trading activity dynamics. Indeed, we would expect trading activity increases in one market subsequent to extreme negative returns (i.e., equivalent to a crisis period) in another market if there were contagion. ${ }^{6}$

Thus far, no role has been left for the investor sentiment and so did classical finance theory for decades. Classical finance theory states that any temporary price deviation from fundamentals are offset by arbitrageurs and as a result, prices reflect all public available information. In such frictionless markets, irrational investors, making sentiment-driven decisions, have no significant impact on prices. Research in the field of behavioral finance, i.e. the 'noise trader' theory of De Long, Shleifer, Summers and Waldman (1990) and the limits to arbitrage theory of Shleifer and Vishny (1997), has shown that security prices do not only depend on systematic risks but that sentiment influences asset valuation too. In other words, current prices do not necessarily equal the discounted value of expected future cash-flows.

This theory is used in the first part of our research to control for herding behavior when the financial mechanisms of contagion are examined. An investor sentiment index as in Lemmon and Portniaguina (2006) and Baker and Wurgler (2006) is included in the asset pricing model which controls for shared risk factors. Baker and Wurgler define the investor sentiment as 'a belief about future cash-flows and investment risks that is not justified by the facts at hand.' By means of this variable, the pricing may chang $\varrho^{7}$ since sentiment may impact asset returns. Hence, the investor sentiment can be a common factor between different asset classes and thus create some comovements between asset classes going beyond the fundamental economic factors. These sentiment-driven comovements parallel the theory by Barberis, Shleifer and Wurgler (2005) which shows that sentiment affects irrational individual investors in a similar fashion, leading them to trade in concert (i.e. herding behavior). Choi and Sias (2009) show that herding behavior also prevails among institutional investors. The argument here is that in order to test for financial mech-

\footnotetext{
${ }^{6}$ Other theoretical papers on the financial channels of contagion include Kiyotaki and Moore (2002), and Allen and Gale (2000) who explore the information and portfolio rebalancing channels, while Kyle and Xiong (2001) and Yuan (2005) show how financial constraints and liquidity are involved in crises and contagion.

${ }^{7}$ The residuals from that model could also change which will have a direct impact on our contagion findings; therefore, the investor sentiment has a certain importance in our setup.
} 
anisms driving contagion it is necessary to control for sentiment-based comovements. Thus, we will not assign contagion mistakenly to financial mechanisms, while the excess comovements could possibly be explained by investor sentiment. Therefore, analyzing contagion with the sentiment variable in the pricing model provides for new insights concerning the importance of sentiment in pricing assets and in explaining return comovements.

As an additional analysis, we test the importance of investor sentiment in a low investor sentiment state of the economy (increasing investor's risk aversion and high volatility) which corresponds to the patterns of a crisis period (of particular interest in our study). The idea is that low investor sentiment and panics may play a role in crises and help their spreading to several markets beyond what is warranted by economic fundamentals. Here, we define 'panic' as a low sentiment (equivalent to pessimism) across various investors in an uncertain environment (i.e., crisis) where behavioral biases and irrationality are supposed to be stronger, thus leading to an increase in trading correlations. The sentiment-based comovement theory explained above is thus applied to a particular state of the economy. So, we specifically test whether herding behavior that is driven by panic could explain contagion.

Our intuition is partly based on the theory of Bacchetta, Tille and van Wincoop (forthcoming) who show that current prices depend on risk about future prices which in turn depends on uncertainty about future risk itself (future risk perceptions). The concept of future risk perceptions is consistent with our definition of investor sentiment (i.e., beliefs about future investment risks). In sum, in the model of Bacchetta, Tille and van Wincoop, risk perception does play a role in pricing assets today by means of its impact on risk today, which would create some (excess) comovements between asset returns that cannot be explained by fundamentals 8 deed, in their framework, the fundamentals do not change, only the way those are read does. Indeed, investors' attention is grabbed by an event and their risk perceptions change accordingly. Hence, self-fulfilling shifts in beliefs about risk appear when the economy switches from a low-risk state to a high-risk state. In this setup, the panic effects (low sentiment prevailing across investors) surrounding stressful times are studied. We reproduce this particular state of the economy and test these predictions by looking how low investor sentiment levels impact the lower tail dependence (our measure of contagion) between two asset returns after having controlled for fundamentals (the same approach as that adopted for the liquidity channel).

\footnotetext{
${ }^{8}$ Using the same theoretical model, Bacchetta and van Wincoop (2012) show how these risk panics may arise on a global scale and thus explain financial contagion.
} 


\section{Empirical Literature}

Besides the theoretical literature discussed above, there are also several empirical studies that address the causes and effects of contagion. Longstaff (2010) focuses on subprime asset-backed collateralized debt obligations and their contagious effects on other major financial markets during the subprime crisis. He shows that contagion is not explained by the information correlation channel and that there were portfolio reallocation activities surrounding the collapse period. He also finds support for the liquidity correlation channel of Brunnermeier and Pedersen (2009). Boyson, Stahel and Stulz (2010) and Dudley and Nimalendran (2011) study whether hedge fund worst returns across different hedge fund styles occur at the same time. In general, their results provide evidence for the importance of liquidity shocks and funding availability in increasing the probability of contagion. Kallberg, Liu and Pasquariello (2005) analyze several countries in Asia and show that contagion between currency and equity returns during the 1997 turmoil happened through information spillover and portfolio rebalancing channels. Boyer, Kumagai and Yuan (2006) is another example of a study that investigates the contagion mechanisms and supports the portfolio rebalancing hypothesis. The authors evaluate the differences in comovements during crises between stocks that are accessible and those that are inaccessible to foreigners. They find that stocks of the first category are more correlated, supporting the importance of international investor holdings in the spread of crashes.

Studies that address the question of the impact of investor sentiment on asset returns and return comovements can be found in the recent empirical literature. Baker and Wurgler (2006) analyze how sentiment affects the cross-section of stock returns and find a negative relationship between sentiment and subsequent returns. They also show that this relationship is significant only for difficult-to-arbitrage stocks (small stocks, young stocks, high volatility stocks, distressed stocks, etc.). Kumar and Lee (2006) is one of the few papers that examines whether stock return comovements are explained by investor sentiment. They use retail investor transactions as a proxy of sentiment and find that it helps to explain return comovement dynamics. Similarly to Baker and Wurgler (2006), they show that difficult-to-arbitrage stocks are more sensitive to sentiment.

Real estate markets have also been the focus of empirical investigations analyzing the impact of sentiment on prices. Clayton, Ling and Naranjo (2009) examine the relevance of sentiment on commercial real estate valuation. Their findings are in line 
with behavioral finance theory, supporting the importance of investor sentiment on pricing even after controlling for fundamentals. Ling, Naranjo and Scheick (2013) evaluate the role played by sentiment in private real estate markets. Their results show a positive short-run effect of investor sentiment on private market returns. They also find that prices slowly revert to their fundamental values due to the limited capacity of arbitrageurs to enter the market because of the short sale constraints and restricted access to credit. Finally, Zhou and Anderson (forthcoming) conduct an empirical investigation of herding behavior in the U.S. REIT market. They find that investors tend to herd more in extreme market conditions, in particular during stressful times.

\section{Models and Empirical Design}

\subsection{Factor Model Specification}

Contagion will lead to a departure from the normal and therefore a standard asset pricing model cannot per se explain contagion as stressed by King and Wadhwani (1990): “[...] it is difficult to come up with a credible story that links 'fundamentals' to a crash" .9 This statement is in line with our definition of contagion which requires correlations over and above what might be expected by economic fundamentals. The purpose of this sub-section is to present an asset pricing model that determines asset returns and therefore controls for the exposure to common risk factors.

This first stage is crucial so that we do not attribute, later in our analyses, a significant relationship related to shared risk factors to contagion. Hence, contagion will not be the natural consequence of the linkages observed under normal conditions, but rather a situation specific to crisis periods. Our model includes variables that have been widely used in the asset pricing literature and that can also be used for pricing real estate assets (Ling, Naranjo and Scheick 2012). Given our cross-asset framework, our asset pricing model needs to be general; so we seek to specify a model that is comprehensive in its scope and hence not necessarily parsimonious. We adopt a multi-factor model approach which is characterized by a linear structure.

We select the 3-month Treasury bill rate, the credit spread (difference between Moody's Baa corporate bond and 10-year U.S. government bond yields) and the term spread (difference between 10-year and 1-year U.S. government bond yields) as business cycle proxies. In addition, the inflation rate and the industrial production

\footnotetext{
${ }^{9}$ King and Wadhwani (1990, p. 6).
} 
growth are included in the model. Liew and Vassalou (2000) show that the size, the book-to-market ${ }^{10}$ and the momentum factors can predict economic growth, thus we also use those factors as additional proxies for the general state of the economy. Moreover, the stock market dividend yield (Fama and French 1988) and the stock market volatility proxied by the VIX index (Ang et al. 2006), which stands for the Chicago Board of Options Exchange volatility index, are included in the model. Finally, the model is augmented with an autoregressive term and an investor sentiment index 11 consistent with 'noise trader' theories. The latter variable takes into account a behavioral dimension of comovements between markets and thus controls for any contribution of such dimension to the financial channels of contagion.

Our multi-factor mode 12 is as follows:

$$
r_{i, t}=\alpha_{i}+\beta_{1, i} r_{i, t-1}+\beta_{2, i}^{\prime} X_{t}+\beta_{3, i} S E N T_{t-1}+\varepsilon_{i, t}
$$

where $r_{i, t}$ denotes asset's $i$ total return and $\beta_{1, i}$ the parameter associated to the autoregressive term. $X_{t}$ represents a $T \times K$ matrix of contemporaneous systematic factors, $\beta_{2, i}$ a $K \times 1$ vector of factor loadings, and $\varepsilon_{i, t}$ the residuals of the model. In this setting, the investor sentiment variable $(S E N T)$ is expressed with a lag in line with behavioral economics literature 13

\subsection{Logit Regression - Contagion Tests}

For the contagion test, we follow Bae, Karolyi and Stulz (2003) and use logit regressions. Logit regressions are appropriate for the estimation of models with dependent variables that have categorial outcomes. This approach allows us to estimate the risk that an asset experiences an extreme negative return given that another asset has an extreme negative return (joint probability). We define 'extreme negative

\footnotetext{
${ }^{10}$ The size and book-to-market factors stem from the Fama-French three-factor model (Fama and French 1993).

${ }^{11}$ We use the University of Michigan consumer confidence index orthogonalized on various macroeconomic variables in order to remove any economic fundamentals they may predict. As a result, we obtain a 'pure' sentiment index.

${ }^{12}$ The market factor is not included in our model since our stock market indices are proxies of the overall stock market which would lead to an important degree of endogeneity in the model biasing the subsequent analyses.

${ }^{13}$ Since the potential mispricing due to sentiment would eventually tend to be corrected (De Long et al. 1990), a lagged sentiment variable is utilized to assess the impact of irrational elements in our setup. The same lagged structure approach is adopted in several papers (e.g., Baker and Wurgler 2006, Lemmon and Portniaguina 2006, and Ling, Naranjo and Scheick 2013). If optimism (pessimism) is related to an overvaluation (undervaluation) of assets, a negative relation between sentiment and future returns is expected; in general, these papers find this result.
} 
return' as a return appearing in the bottom decile of the distribution of returns and we create indicator variables taking the value of one if this argument is true, and zero otherwise. A $10 \%$ cutoff allows us to focus on the lower tail distribution of returns, which is of interest in contagion analyses, while providing a sufficiently large number of observations to yield meaningful results.

In order to be consistent with the Bekaert, Harvey and Ng (2005) definition of contagion, we perform the contagion tests on the residuals stemming from the multifactor model (filtered returns). We constitute pairs of assets and evaluate the ability of an asset to increase the probability of another asset having an extreme negative return. Each pair is estimated separately. Since the dependent variable is binary, we estimate binomial logit models (by maximum likelihood) which yields to the estimation of two parameters (the constant and the coefficient of the independent variable) in each model. A positive and significant coefficient on the independent variable, which is another asset's extreme negative return indicator variable, would indicate evidence of contagion. To assess the economic significance of the statistical results of the logit model, the probabilities of observing an extreme negative return for an asset conditional on another asset having an extreme negative return (clustering of worst returns) are calculated based on the estimated coefficients and then compared to the base case (no 'extreme negative return').

\subsection{Information Correlation Channel}

A quantile regression approach (Koenker 2005) is adopted for investigating the information correlation channel. The modeling consists of expressing quantiles of the conditional distribution of a dependent variable as a function of regressors. The hypothesis of the correlated information channel stipulates that the news emanating from one market impact the low returns of another market. Therefore, we examine the predictive ability of an asset on the lower quantiles of another asset return distribution.

To test this hypothesis, the returns of asset $i$ are regressed on the lagged returns (of order one) of asset $j$, and vice versa. In keeping with the definition of contagion proposed by Bekaert, Harvey and Ng (2005), we further control for economic fundamentals in our quantile regression analyses by including the variables presented in section 4.1, except for the $\operatorname{AR}(1)$. Thus, if the causality appears over a short period of time (i.e. with a one period lag), the shocks are indeed transmitted through information since one asset's price changes are relevant for the pricing of another asset even though economic fundamentals have been controlled for. Accordingly, 
the quantile regression estimated is as follows:

$$
q_{t}\left(\theta, r_{i, t} ; \beta(\theta), \Phi(\theta)\right)=\beta_{0, i}(\theta)+\beta_{1, i}(\theta) r_{j, t-1}+\beta_{2, i}(\theta) S E N T_{t-1}+\Phi_{i}^{\prime}(\theta) X_{t}+\eta_{i, t}
$$

where $r_{i, t}$ and $r_{j, t}$ are the assets' $i$ and $j$ total returns, respectively. $\theta$ indicates a given quantile (e.g., 0.25). $\beta_{1}(\theta)$ is the parameter showing the effect of an asset upon another while $\beta_{2}(\theta)$ estimates the impact of the sentiment variable. $\Phi(\theta)$ represent the vector parameters of the control variables. The error term is represented by $\eta_{i, t}$. Quantile regressions allow us to specifically examine the effects on low returns consistent with the notion of contagion; therefore our methodology is well suited in this respect, which would not be the case of standard OLS analysis. Indeed, although simple and easy to implement, OLS provides estimates of the effects on the conditional mean of returns. In addition, a direct effect from one asset's returns to another can be set up and assessed as required by the information correlation channel test.

\subsection{Liquidity Correlation Channel}

The liquidity channel hypothesis is investigated within a copula framework. A copula is a function that joins or couples two or more marginal distribution functions. We use this methodology for modeling the dependence structure between our asset returns. Let $X$ and $Y$ be two random variables with $F_{X}(x)$ and $F_{Y}(y)$ their respective marginal distribution functions and $F_{X Y}(x, y)$ their joint distribution function. According to Sklar (1959), there exists a function $C$ called copula that joins the previous marginal distributions:

$$
F_{X Y}=C\left(F_{X}(x), F_{Y}(y)\right)
$$

where $C$ covers all possible bivariate distribution functions. Then, if we set $u=$ $F_{X}(x)$ and $v=F_{Y}(y)$ with $0 \leq u \leq 1,0 \leq v \leq 1$ where both are uniformly distributed, we obtain a function $C(u, v)$ defined on a unit rectangle. The estimation procedure requires two steps and a semi-parametric approach is adopted. In the first step, we filter our return series by an AR(1)-GJR-t-GARCH(1,1) 14 augmented with the factors used in our multi-factor model (see Equation 1). By using a GARCH

\footnotetext{
${ }^{14}$ Our return volatilities follow an univariate generalized autoregressive conditional heteroskedasticity $(\mathrm{GARCH})$ process with asymmetry, which is expressed as in Glosten, Jagannathan and Runkle (1993).
} 
model, we take into account the time-varying variance and the heteroskedasticity of the model residuals. The variance equation of the residuals stemming from the mean equation (the asset pricing model presented in section 4.1) is as follows:

$$
\begin{gathered}
\varepsilon_{t} \mid \Phi_{t-1} \sim \text { Student }-t\left(0, \sigma_{t}^{2}, \nu\right) \\
\sigma_{t}^{2}=\alpha_{0}+\alpha_{1} \varepsilon_{t-1}^{2}+\beta \sigma_{t-1}^{2}+\phi \mathbb{1}_{\varepsilon_{t-1<0}} \varepsilon_{t-1}^{2}
\end{gathered}
$$

where $\mathbb{1}_{\varepsilon_{t-1<0}}$ is a binary variable which takes the value of one if the error term is negative, zero otherwise. $\nu$ equals the degrees of freedom of the $t$-distribution and partially captures the fat tail feature of the data. Then, a nonparametric estimation of the marginal distributions is performed by means of an empirical cumulative distribution function (cdf) based on the standardized residuals coming from the filtering process presented above.

In the second step, the copula function is estimated parametrically (i.e., maximum likelihood estimation) based on the marginal distributions obtained in the first step. The symmetrized Joe-Clayton (SJC) copula with time-variation (Patton 2006) is chosen to model the dependence structure of our asset returns. In a bivariate static form, the SJC copula, which is a modification of the Joe-Clayton (JC) copula of Joe (1997), is expressed as follows:

$$
\begin{aligned}
C_{S J C}\left(u_{1}, u_{2} ; \tau^{U}, \tau^{L}\right)= & 0.5 \cdot\left(C_{J C}\left(u_{1}, u_{2} ; \tau^{U}, \tau^{L}\right)+C_{J C}\left(1-u_{1}, 1-u_{2} ; \tau^{U}, \tau^{L}\right)\right. \\
& \left.+u_{1}+u_{2}-1\right)
\end{aligned}
$$

where:

$C_{J C}\left(u_{1}, u_{2} ; \tau^{U}, \tau^{L}\right)=1-\left(1-\left\{\left[1-\left(1-u_{1}\right)^{\kappa}\right]^{-\gamma}+\left[1-\left(1-u_{2}\right)^{\kappa}\right]^{-\gamma}-1\right\}^{-1 / \gamma}\right)^{1 / \kappa}$

and where $\kappa=1 / \log _{2}\left(2-\tau^{U}\right), \gamma=-1 / \log _{2}\left(\tau^{L}\right)$ and $\tau^{U} \in(0,1), \tau^{U} \in(0,1) . \tau^{U}$ and $\tau^{L}$ are the two parameters of the SJC copula and represent the upper and lower tail dependences, respectively.

The lower tail dependence derived from the SJC copula will constitute our measure of the intensity of contagion. Since contagion involves financial markets that perform poorly, a copula allowing for dependence in the left tail of the distribution is of interest. This feature motivates our choice for the SJC copula. For the purposes of our study, we will mostly concentrate on the implications of the model for the 
lower tail dependence. In our copula framework, the lower tail dependence is defined as:

$$
\tau^{L}=\lim _{q \rightarrow 0} P(U \leq q \mid V \leq q)=\lim _{q \rightarrow 0} P(V \leq q \mid U \leq q)=\lim _{q \rightarrow 0} \frac{C(q, q)}{q}
$$

where $U=F_{x}(x)$ and $V=F_{y}(y)$. There is a lower tail dependence if the previous limit exists and $\tau^{L} \in(0,1]$.

To test for the liquidity correlation mechanism underlying the contagion phenomenon, we follow Dudley and Nimalendran (2011). We use a conditional SJC copula à la Patton (2006) in order to allow the lower tail dependence to evolve across time and include variables related to funding liquidity and commonality in liquidity in the model ${ }^{15}$ The model is as follows:

$$
\tau_{t}^{L}=\Lambda\left(\omega+\beta \tau_{t-1}^{L}+\alpha \frac{1}{10} \sum_{j=1}^{10}\left|u_{1, t-j}-u_{2, t-j}\right|+\delta^{\prime} X_{t}\right)
$$

where $\Lambda(x)=\left(1+e^{-x}\right)^{-1}$ is the logistic transformation. This transformation constrains the tail dependences to stay in $(0,1)$ during the entire period. This expression is akin to an ARMA $(1,10)$ with exogenous variables and its parameters are estimated by maximum likelihood. $\delta$ includes the parameters of interest as the vector $X_{t}$ contains the variables of the channels of contagion (i.e., credit availability and commonality in liquidity). Thus, significant $\delta$ s would mean that contagion happened through a liquidity mechanism and would therefore provide support to the theoretical work of Brunnermeier and Pedersen (2009).

Our methodology based on copulas has three main advantages. First, since extreme negative returns are of concern in the analysis of contagion, a method allowing for lower tail dependence represents an important feature. Further, it is well established in the literature that the dependence between financial series is not linear 16 Copulas address this issue as they allow for nonlinearity in the dependence structure. Finally, the method we adopted for expressing time-variation in the dependence measure provides us with much more stable results than those emanating from a moving window approach. Although this method is simple and popular, its results are very sensitive to the observations used in each window.

\footnotetext{
${ }^{15}$ The time-varying upper tail dependence is modeled in a similar fashion.

${ }^{16}$ See, for instance, Embrechts, McNeil and Straumann (2002).
} 


\subsection{Portfolio Rebalancing Channel}

The test of the portfolio rebalancing mechanism relies on the analysis of the trading activity dynamics of the various markets studied. The changes in dollar trading volume are utilized as proxy for the trading activity. We test whether or not poor performances in market $j$ are associated with an increase of the trading activity in market $i$, and vice versa. We express the poor performances by creating an indicator variable set to one if the return is in the lowest decile of the return distribution and zero otherwise. Thereby, we would expect, under the portfolio rebalancing hypothesis, that poor performances in one market would have a significantly positive impact on the trading volume of the other market. This would mean that investors react to the shocks coming from one market by reallocating their resources in other markets. This latter test is carried out by means of time series regressions. We also use a set of other explanatory variables that may affect trading activity as well as an autoregressive term. The model estimated is as follows:

$$
y_{i, t}=\mu+\beta y_{i, t-1}+\gamma^{\prime} Y_{t-1}+\phi^{\prime} X_{t}+\delta^{\prime} Z_{j, t-1}+\varepsilon_{i, t}
$$

where $y_{i, t}$ represents the variations in dollar trading volume of asset $i$ and $Y_{t}$ those of the three other assets. $X_{t}$ contains the weekly first differences in the 3 -month T-bill rate, the term spread and the credit spread. These variables have been chosen according to the paper by Chordia, Roll and Subrahmanyam (2001) who show that those factors can help explain the trading activity patterns. The indicator variable that encompasses the lowest returns of the asset $j$ and its continuous winsorized variable (to avoid the double counting of the lowest returns) are denoted by $Z_{j, t}$. The indicator variable will show us whether extremely low returns in market $j$ affect

the volume traded in market $i$ which would be supportive of the portfolio rebalancing channel hypothesis. The ability of REIT returns to forecast stock market trading activity as well as the reverse are investigated, which yields to the estimation of six different models.

\subsection{Investor Sentiment}

The analysis of the investor sentiment hypothesis takes two forms, namely the test of the sentiment-induced comovements in the spirit of Barberis, Shleifer and Wurgler (2005) and the test of the panic effects present in stressful times. Whether investors mimicking each other creates some return comovements is examined by means of the multi-factor model (Equation 1). If so, we would expect the sentiment variable to 
be a significant pricing factor across the various assets. Hence, we will also be able to assess if our financial channels of contagion are independent of any behavioral dimension in the markets. Then, we adopt the same methodology as for the liquidity correlation channel and estimate Equation 7(i.e., time-varying lower tail dependence model with exogenous variables) by including a sentiment-based variable in the model. We believe that the combination of low investor sentiment (increasing risk aversion) and lower tail dependence replicates well a panic phenomenon at play in the spreading of a crash. Under such an hypothesis, we would expect a negative link between sentiment and our contagion measure. Thereby, this model allows us to see whether a particular state of the investor sentiment is connected to the clustering of worst returns between different asset classes.

\section{Data Description}

\section{$5.1 \quad$ Variables}

The issue of tracking real estate price changes accurately has been debated for decades and is still ongoing. In this paper, REIT data have been selected to proxy for real estate returns and have been collected from NAREIT. Since contagion is a short-term phenomenon, this supports the utilization of real estate security indices as high frequency data are requested to perform this analysis. Potential accuracy issues concerning direct real estate indices also support the use of real estate security indices as a proxy for real estate markets (Subrahmanyam 2007). Further, REIT returns are levered returns which correspond better to investment practice in real estate markets. Also, the literature has shown that real estate shocks take first place in REIT market and then the direct market reacts accordingly (Hoesli and Oikarinen 2012), which constitutes further evidence that REITs are a reliable proxy for real estate in our case. Three different sub-indices of the equity market are investigated: Small-cap stocks (S\&P 600 index), large-cap stocks (S\&P 500 index), and a stock index for commercial banks (S\&P 500 Banks index). These series are expressed in total returns. All data related to the stock market have been sourced from Thomson Reuters Datastream.

The data used to construct the different variables of the multi-factor model have been collected from various sources. The size and book-to-market factors (Fama and French 1993) as well as the momentum factor are obtained from Kenneth French's 
website ${ }^{17}$ We use the 10-year and 1-year U.S. government bond yields, the Moody's Baa corporate bond yields and the 3-month Treasury bill rate, available on the Federal Reserve Board website, to construct the business cycle variables. As for the industrial production, the inflation rate and the VIX index, the data are collected from Thomson Reuters Datastream. Finally, data from the University of Chicago's Center for Research in Security Prices (CRSP) are used to construct the dividend yields.

The University of Michigan consumer confidence index (sourced from Thomson Reuters Datastream) is chosen as the investor sentiment variable. This index is based on surveys that poll U.S. households on their current financial situation and their expectations about the future of the U.S. economy. Since this investor sentiment index may reflect to some extent economic fundamentals, it is necessary to control for such confounding effects by orthogonalizing the index on various macroeconomic variables. Lemmon and Portniaguina (2006) find that the University of Michigan consumer confidence index predicts future macroeconomic activity. So, they filter the index from those factors and conjecture that the unexplained proportion represents a 'pure' sentiment index that is unrelated to economic fundamentals. We proceed to perform the same filter and regress the raw index on seven macroeconomic variables: Growth in industrial production, growth in durable, nondurable and services consumption, growth in employment, inflation, and an NBER recession indicator. The levels of the filtered index are used in our analyses. The University of Michigan index is preferred to the Baker and Wurgler (2006) index, another popular investor sentiment index, for two reasons. First, it is a direct measure of sentiment since based on surveys, whereas the Baker and Wurgler index is an indirect measure. Second, it has the advantage to proxy for sentiment in the overall economy and not only for the general stock market. This is of importance in our study as we have taken a cross-asset perspective for the contagion investigation.

We use the dollar trading volume as our measure of trading activity for the portfolio rebalancing hypothesis test. As for the liquidity correlation channel, we need proxies for funding liquidity related to the REIT and stock markets. As funding liquidity variables, we use the variations in the TED spread, the difference between the 3-month commercial paper rate and the 3-month Treasury bill rate (commercial paper spread), and the variations in spread between the 30 -year conventional mortgage rate and the 3-month Treasury bill rate (mortgage spread). Increased spreads imply higher borrowing costs, that is a narrowing of the funding liquidity.

\footnotetext{
${ }^{17}$ http://mba.tuck.dartmouth.edu/pages/faculty/ken.french
} 
The extant literature has shown that those indirect measures of aggregate supply of funding are relevant. The data needed to construct those variables are collected from the Federal Reserve Board website.

As for market liquidity, we employ the Amihud's (2002) illiquidity measure. The Amihud's measure captures the market depth (price impact measure of liquidity) and equals:

$$
I L L I Q_{i w}=\frac{1}{D_{i w}} \sum_{t=1}^{D_{i w}} \frac{\left|R_{d w}^{i}\right|}{V O L D_{d w}^{i}}
$$

with $R_{d w}^{i}$ and $V O L D_{d w}^{i}$, the return on stock $i$ on day $d$ of week $w$ and the respective daily volume. To construct these measures, prices, shares outstanding, and trading volume at the daily frequency are needed for each constituent of our indices (then weekly averages are constructed). Then, each measure at the firm level is aggregated at the index level (i.e., equally-weighted). All data have been collected from CRSP and Thomson Reuters Datastream.

Commonality in liquidity constitutes the last variable we use for testing the correlated liquidity channel. This channel stipulates that a shock to one market reduces the liquidity in many markets (increase in liquidity commonality), which would eventually affect the behavior of asset prices and their comovements. So, we need to define a dependence measure in order to capture the commonality in liquidity between assets. We express this commonality in liquidity by looking at the correlation between two assets' liquidity variations (stemming from the liquidity levels calculated by means of Equation 10. Thereby, this variable will show whether the movements in liquidity are correlated across markets. Again, we rely on copulas for constructing this variable and more specifically on the normal copula whose unique parameter is the correlation level $\rho$. The bivariate normal copula ${ }^{18} C_{N}\left(v_{1}, v_{2}\right)$ takes the form:

$$
C_{N}\left(v_{1}, v_{2} ; \rho\right)=\int_{-\infty}^{\Phi^{-1}\left(v_{1}\right)} \int_{-\infty}^{\Phi^{-1}\left(v_{2}\right)} \frac{1}{2 \pi \sqrt{1-\rho^{2}}} \exp \left[\frac{-\left(r^{2}-2 \rho r s+s^{2}\right.}{2\left(1-\rho^{2}\right)}\right] d r d s
$$

where $\Phi^{-1}$ is the inverse of the standard normal $c d f$. To allow the correlation

\footnotetext{
${ }^{18}$ The estimation procedure is similar to that of the SJC copula, i.e. a 2-step semi-parametric estimation. First, we filter our series with an AR(1)-GJR-t-GARCH(1,1) and estimate the marginal distribution $v_{1}, v_{2}$ by means of an empirical $c d f$. Second, the copula function is estimated parametrically by maximum likelihood.
} 
parameter $\rho$ to vary across time, we adopt the same approach as for the lower tail dependence parameter (Equation 8) and specify a conditional normal copula as proposed by Patton (2006). The equation for $\rho_{t}$ is the following:

$$
\rho_{t}=\tilde{\Lambda}\left(\omega_{\rho}+\beta_{\rho} \rho_{t-1}+\alpha_{\rho} \frac{1}{10} \sum_{j=1}^{10} \Phi^{-1}\left(v_{1, t-j}\right) \Phi^{-1}\left(v_{2, t-j}\right)\right)
$$

where $\tilde{\Lambda}(x)=\left(1-e^{-x}\right)\left(1+e^{-x}\right)^{-1}$ is the modified logistic transformation, which ensures that $\rho_{t}$ remains bounded between -1 and 1 at all times.

As mentioned above, relatively high frequency data are needed for analyzing contagion. For instance, Longstaff (2010) explains that contagion is 'rapid and temporary' and Kaminsky, Reinhardt and Végh (2003) say that contagion must be 'fast and furious'. As a result, we will use weekly data 19 for conducting our investigations. The time period goes from January 1, 1999 through September 30, 2011.

\subsection{Descriptive Statistics}

Weekly raw returns for the selected indices, i.e. REITs, S\&P 600, S\&P 500 and S\&P 500 Banks, are summarized in Panel A of Table1. All indices exhibit a positive average return over the 1999-2011 period except for commercial banks that exhibit a negative mean return $(-0.09 \%)$. These observations are consistent with the skewness values that show a positive value only for the bank index (0.20). These results show the poor performance of the U.S. banking sector during our sample period. The S\&P 500 Banks' sector is the riskiest asset class with a standard deviation of $5.14 \%$, as compared to that of REITs (3.53\%), the S\&P 600 (3.24\%), and the S\&P 500 $(2.74 \%)$. All raw return series are leptokurtic asserting the importance of extreme observations in the return distributions 20

\section{[Table 1 about here]}

\footnotetext{
${ }^{19}$ The weekly momentum factor is constructed from daily data since data are not available at the weekly frequency. Linear interpolation is used for obtaining weekly investor sentiment indexes (gradual evolution) as they are only available at the monthly frequency. This seems reasonable since the investor sentiment does not show an erratic tendency in the short-term. Weekly industrial production growth and inflation rates are also constructed using linear interpolation.

${ }^{20}$ All series are stationary based on the results of the augmented Dickey-Fuller test with trend and four lags (not reported); thus the series do not need to be transformed before the models are estimated.
} 
Panel B reports the summary statistics for each asset liquidity measured as the inverse of the Amihud's (2002) illiquidity measure. As expected, the S\&P 500 Banks and the S\&P 500 are the most liquid indices (4041 and 3015, respectively) while small caps and REITs have the lowest liquidity levels (48 and 3, respectively). As a first step in the analysis of the interdependences between markets, unconditional correlations between filtered returns are evaluated (Panel C). All indices are positively correlated providing preliminary evidence of financial contagion.

\section{Estimation Results}

The empirical analysis consists of three parts. First, the results of the asset pricing model estimation which aims to control for the exposure to common risk factors are discussed. Second, the findings from the contagion test (using logit regressions) are analyzed in order to verify whether there was contagion between real estate and financial markets during our sample period. Finally, the financial and behavioral channels of contagion are investigated by means of three econometric methods: i) quantile regressions, ii) copulas, and iii) time series regressions. This final section will shed some light on the underlying mechanisms of crash spreading.

\subsection{Model Estimation}

Table 2 provides the multi-factor model estimates where each asset's returns (i.e. REITs, S\&P 600, S\&P 500 and Banks) are regressed on a number of well-known variables from the asset pricing literature (see Equation 1). This model aims to control for common economic fundamentals between REIT and stock returns so that financial contagion is not confounded, later in our analyses, with comovements pertaining to shared risk factors. The results provide formal support to the specification of our asset pricing model with an important number of highly significant coefficients (based on Newey-West adjusted $t$-values) and relatively high adjusted$R^{2}$ values ranging from 0.52 for the REITs to 0.72 for the S\&P 600 . These results argue against the risk that return comovements related to shared risk factors would be attributed to contagion.

$$
\text { [Table } 2 \text { about here] }
$$

In general, the factor loadings present relatively consistent patterns with the extant empirical asset pricing literature. We uncover that innovations in aggregate 
market volatility $(\Delta V I X)$ are negatively associated to returns and the related parameters are significant at the $1 \%$ confidence level. This finding implies that investors are willing to pay to hedge themselves against increases in market volatility (Ang et al. 2006). HML, MOM and Credit Spread are also significant pricing factors. This latter factor shows that shifts in economic conditions give rise to pricing implications for the assets studied. The remaining variables exhibit little or no significant effect on asset returns.

We expect that noise trader sentiment, in the wake of the growing behavioral finance literature (e.g. Baker and Wurgler 2006), could play a role in our framework. To investigate the incremental ability of investor sentiment to explain asset returns, we include a lagged sentiment index as an additional factor in the regressions. Nevertheless, this variable does not have a significant impact on the asset returns, which contrasts with recent literature. We explain these differences by the fact that in previous studies, the investor sentiment is tested on different categories of stocks. Those studies show that sentiment is relevant for pricing only certain types of stocks (e.g. young stocks, small stocks, high volatility stocks, etc.). Therefore, since we include this variable at the index level, the impact of sentiment on specific types of stocks might have been smoothed out by the fact that other categories of stocks in the index are not sensitive to this variable.

As a preliminary interpretation, those findings suggest that there are no comovements induced by sentiment in the spirit of Barberis, Shleifer and Wurgler (2005) between the four indexes analyzed in this paper given that sentiment is not a significant common factor. However, this result is valid only in 'normal' market conditions and therefore does not rule out the possibility of sentiment-based contagion. Whether sentiment affects the risk of contagion is the purpose of the next sections.

\subsection{Contagion}

Before analyzing contagion channels, it is paramount to assess whether contagion indeed occurred. Table 3 shows the estimates of the logit regressions and a very clear pattern of contagion between real estate and equity markets during the period 19992011 is found ${ }^{21}$ Indeed, the parameters are positive and highly significant in each case. On average, the parameters take values of about 2.5 and the $t$-statistics are higher than 7, witnessing for the robustness of our results. Thus, the risk of having

\footnotetext{
${ }^{21}$ Similar results are found if we use a $25 \%$ cutoff for the indicator variables. These results are not reported but can be obtained upon request.
} 
an extreme negative return increases when the other market performs poorly. These results tell us that there are return comovements in excess of what one would expect based on economic fundamentals, consistent with the Bekaert, Harvey and Ng (2005) definition of contagion. The pseudo $R^{2}$ of our logit models range from $10 \%$ (Banks) to $18 \%$ (S\&P 600).

[Table 3 about here]

Since the interpetation of the above parameters is not straightforward, we assess their economic significance by calculating the increase in probability of observing a worst return in one market conditional on the fact that the other market exhibits a worst return (joint occurrence). This probability increases by $42.8 \%, 36.1 \%$ and $31 \%$ (in absolute terms) when investigating the pair REITs-S\&P 600, REITs-S\&P 500 and REITs-S\&P 500 Banks, respectively. We observe that the intensity of contagion is the highest between real estate and small cap stocks and that these probabilities are quite high across the various pairs supporting the hypothesis of contagion.

\subsection{Contagion Channels}

In this section, the nature of the contagion identified previously is investigated. First, we analyze three financial channels of contagion: Information correlation, liquidity correlation and portfolio rebalancing. Then, we examine whether or not investor sentiment and panic represent an underlying driver of excess comovements. Finally, we also look at the impact of the significant factors explaining contagion on the upper tail dependences (excess return comovements in good times). This section permits to identify any asymmetric effects coming from the factors influencing the risk of contagion.

\subsubsection{Financial Mechanisms}

The information correlation channel is tested by means of quantile regressions. As stressed by Longstaff (2010), this channel involves the transmission of information from one market to another within a very short period of time. Thereby, its testing requires to evaluate the speed of information transmission between two markets and quantile regressions are a suitable framework for such testing. Indeed, a lagged relationship can be set up between two asset classes and the null hypothesis of no such lag effect can be tested directly. In keeping with our definition of contagion, control variables as in Equation 1 are added to this basic quantile regression. The models 
are estimated for the 10th and 50th quantiles; the latter model being estimated for comparison purposes. A significant positive parameter on the lagged return variable for the 10th quantile would argue for the correlated information channel. Table 4 displays the estimation results of our models. The results for the control variables are not reported for economy of space; however, they are not economically different from those stemming from the multi-factor model (Table 2). Analyses of contagion via information mechanisms from the real estate market to the equity market (Panel A) and vice versa (Panel B) are both conducted.

\section{[Table 4 about here]}

Estimation results from Table 4 show that the lagged returns have no effect on the bottom quantile of the distribution of returns (in both cases), even though all coefficients have the expected sign 22 No parameter is significant at the conventional confidence levels based on $t$-statistics calculated on robust standard errors. Therefore, markets' low return dynamics are not driven by the information stemming from another market. This finding strongly rejects the theory of King and Wadhwani (1990). Our finding is not an isolated result in the literature. For instance, Longstaff (2010) also shows that the correlated information channel is not able to explain the dynamics of financial contagion he documents. The results of the 50th quantile regressions do not provide us with new insights. Thus, by ruling out this channel, we are left with the possibility that other mechanisms should underlie the contagion documented in the previous section.

For testing the liquidity correlation channel as proposed by Brunnermeier and Pedersen (2009), we estimate a time-varying symmetrized Joe-Clayton copula with exogenous variables related to funding liquidity and commonality in liquidity. In other words, the time-varying (upper and lower) tail dependences between REIT and stock returns 23 are modeled as a function of liquidity variables and an ARMA $(1,10)$ process. In this section, we only report the results pertaining to the lower tail dependence as it represents our measure of contagion. The impacts of credit availability and commonality in liquidity on three pairs of assets are examined: REITs-S\&P 600, REITs-S\&P 500, and REITs-Banks. The tests of the funding liquidity and the commonality in liquidity are conducted separately.

\footnotetext{
${ }^{22}$ Similar results are found if we estimate the models for the 25 th quantile. These results are not reported but can be obtained upon request.

${ }^{23}$ The returns are the residuals from the asset pricing model standardized according to an univariate GJR-t-GARCH( $(1,1)$ process.
} 
In the first test, we take as credit availability proxies the variations in the TED spread (TEDSP), the commercial paper spread (CPSP) and the 30-year conventional mortgage spread $(M T G S P)$; higher spreads would represent a tightening of credit accessibility. The model is estimated separately for each funding liquidity variable. In order to control for any confounding effects caused by asset liquidity, we also include each asset's liquidity in the model. Since the inverse of the Amihud's illiquidity measures $(L I Q)$ are right skewed (see Table 1), the natural logarithms of these measures are taken as asset liquidity variables. Contemporaneous liquidity variables are utilized. The estimation is performed by maximum likelihood and the $t$-statistics are based on asymptotic standard errors. The results are reported in Table 5 .

[Table 5 about here]

The parameters of the ARMA $(1,10)$ part of the specification, which corresponds to the basic version of the model as suggested by Patton (2006), exhibit consistent patterns with the extant literature. The autoregressive term has a strong predictive power with parameters mostly significant, whereas the moving average term shows more mixed features with fewer statistically significant parameters. Turning now to the variables of interest for testing the liquidity spiral hypothesis, Table 5 shows that our results are less supportive of this channel as a contagion mechanism than what has been reported in previous studies (e.g. Boyson, Stahel and Stulz 2010; Longstaff 2010). In order to verify the theoretical predictions of Brunnermeier and Pedersen (2009), a positive relationship is expected between the difficulty to obtain funding (increased spreads) and the likelihood of contagion. We uncover that the commercial paper and the TED spreads have a significantly positive effect on the lower tail dependences between REITs and small cap stocks, but this result is not robust across the various pairs. Indeed, the other parameters are either inconsistent with the funding channel or insignificant. We conclude that funding liquidity can explain contagion but that it is not necessarily relevant in all cases, nuancing therefore the scope of the Brunnermeier and Pedersen's theory. As regards the asset liquidity variables, they do not show consistent effects on the lower tail dependence parameter.

In the second test, we use the correlation between assets' liquidity variations, coming from a conditional normal copula, as our proxy for commonality in liquidity and include it in the conditional SJC copula as an exogenous variable. The estimation results of this model are reported in Table 6. Again, the parameters related to the ARMA specification are consistent with the existing literature. As regards 
the commonality in liquidity, this factor exhibits a greater explanatory power than funding liquidity. Commonality in liquidity appears to be significant (at the $5 \%$ confidence level) and positive for two pairs, i.e. REITs-S\&P 600 and REITs-Banks, implying that the risk of contagion increases with the liqudity correlation across markets. In other words, liquidity, that tends to decrease in several markets in stressful times (increase of the commonality in liquidity), adversely impacts market prices and increases thereby their comovements. Thus, contagion arises due to the tight relations between markets' liquidity.

\section{[Table 6 about here]}

Overall, these findings argue for a correlated liquidity mechanism underlying contagion between real estate and financial markets, even though the results related to funding liquidity are less clear-cut than those of previous studies. So, commonality in liquidity is not exclusively driven by funding dynamics. This conclusion parallels the recent empirical work by Karolyi, Lee and van Dijk (forthcoming) who question the financing approach of Brunnermeier and Pedersen (2009) by showing that demand-side determinants are more important than supply-side ones in explaining liquidity and commonality in liquidity.

Finally, the portfolio rebalancing channel is explored by means of time series regressions. Each indice's changes in dollar trading volume (i.e. $\triangle$ REIT Volume, $\Delta S \& P 600$ Volume, $\Delta S \& P 500$ Volume, and $\Delta$ Banks Volume) is regressed on the trading volumes of the other markets (lagged variables) as well as on its own lagged values. Furthermore, two sets of variables are added to the model. First, the differences in the 3-month T-bill, the term spread and the credit spread are chosen as they likely affect trading activity (Chordia, Roll and Subrahmanyam 2001). Second, an indicator variable that takes the value of one if the returns of the distressed asset are in the lowest decile of the distribution and its winsorized continuous variable are also included to assess the ability of worst returns to forecast the trading patterns of another market. The first set of variables are contemporaneous whereas the second are expressed with one lag. The key variable in this model is the indicator variable which, if significantly positive, would imply that poor performance in one market increases the trading activity in another market; contagion would thus have occurred through portfolio reallocation activities.

The estimation results of the time series regressions, where the ability of low REIT returns to predict stock market trading activity is explored, are displayed in Table 7. Focusing first on the mutual dynamics between the different trading 
volumes, Table 7 shows that $\Delta$ REIT Volume does not affect the trading volume in the stock market. On the other hand, the trading volumes of the three stock indices have strong predictive ability for their respective trading volume and that of the two others. The coefficients of $\Delta S \& P 600$ Volume and $\Delta$ Banks Volume are negative and those of $\Delta S \& P 500$ Volume positive. All parameters are significant at the $1 \%$ confidence level based on Newey-West adjusted $t$-statistics. Those results show the important connections existing between the trading activities of different assets on U.S. financial markets.

\section{[Table 7 about here]}

Chordia, Roll and Subrahmanyam (2001) find that long- and short-term interest rates influence liquidity and trading activity, so we control for those factors to avoid any confounding effects. Except for the 3-month T-bill, we find that those variables have little influence on trading volumes in stock markets. Focusing now on the variables of interest for our portfolio rebalancing test (i.e., indicator variables), no evidence of worst real estate returns impacting subsequent changes in trading volumes in financial markets is found. The winsorized continuous variables do not exhibit a more pronounced relation with stock market trading volumes; indeed, none of the coefficients is significant.

The results of the regressions that include indicator variables encompassing the lowest returns of the different stock markets are reported in Table 8. The trading volumes in stock markets are significant variables for explaining the trading volume variations in the REIT market. The autoregressive term is also significant at the $1 \%$ confidence level. The changes in T-bill rate and in the term spread turn to be highly significant now, whereas the variations in credit spread remain insignificant. Again, the coefficients of the indicator variables are not consistent with the portfolio rebalancing hypothesis. Thus, we strongly reject the possibility that activities of market participants in optimally readjusting their portfolios could explain the contagion between real estate and financial markets.

$$
\text { [Table } 8 \text { about here] }
$$

In summary, the analyses of the financial mechanisms of contagion provide us with one leading channel underlying the contagion between real estate and financial markets, i.e. the liquidity correlation channel. The two other financial mechanisms do not exhibit a significant role. Indeed, we do not find any evidence that shocks spilled over markets via information as suggested by King and Wadhwani (1990), 
and we also strongly reject the portfolio rebalancing channel introduced by Kodres and Pritsker (2002).

\subsubsection{Behavioral Mechanisms}

This section is devoted to the question of whether or not a behavioral dimension is present in financial contagion. In a preliminary analysis, we found that the investor sentiment is not a common factor across the different assets (see Table 2) which argues against the sentiment-based comovement theory of Barberis, Shleifer and Wurgler (2005). However, this finding is valid only in 'normal' market conditions and does not tell us much about the behavior of sentiment in extreme situations. Therefore, we need to further examine the investor sentiment as an underlying channel of contagion to fully understand the role played by sentiment in financial markets. More precisely, we explore the possibility that sentiment is a vector of financial contagion based on the intuition that panic grips market participants during market downturns.

Here, we investigate the sentiment channel by means of the same copula model as for the liquidity channel but include the investor sentiment variable in the model instead of the liquidity variables ${ }^{24}$ The sentiment variable stems from the University of Michigan consumer confidence index net of various macroeconomic variables, which yields a 'pure' sentiment index, and is a proxy for market optimism/pessimism. The levels of this index are utilized in our model and the contemporaneous effects of this variable are explored. The results are reported in Table 9. Regarding the ARMA $(1,10)$ part of the model, the results are consistent with those of the liquidity correlation channel model (Tables 5 and 6).

\section{[Table 9 about here]}

Theoretically, we predict that high pessimism would increase the likelihood of contagion and therefore a negative contemporaneous relationship is expected between sentiment and lower tail dependences. We conjecture that the combination of low sentiment25 and worst return comovements is a reliable indicator of panic amongst investors in stressful periods. We find strong evidence of a negative association between the level of our sentiment index and the risk of contagion for the

\footnotetext{
${ }^{24}$ In order to avoid double counting the sentiment factor, the residuals from an asset pricing model without the investor sentiment variable are used in this analysis.

${ }^{25}$ As suggested by 'noise trader' theories, sentiment should bias the behavior of irrational investors but it is not ruled out that institutional investors would also be affected.
} 
pairs REITs-S\&P 600 and REITs-S\&P 500. The parameters are significant at the $1 \%$ and $5 \%$ confidence levels, respectively. As regards the REITs-Banks pair, we do not find a statistically significant relationship between the lower tail dependence and the investor sentiment even though the parameter has the expected sign (negative).

We note that the lower tail dependences between real estate and small cap stock returns are the most affected by sentiment, consistent with the idea that sentiment affects the most non-institutional investors as these are more likely to buy small cap stocks. Those findings suggest that when a market performs extremely poorly, this event grabs investors' attention and changes their risk perceptions (increase of pessimism/decrease of sentiment). In turn, this panic arises on a global scale and reaches other assets that also experience price declines. These results are consistent with some important events that took place during the recent financial crisis. Several large U.S. REITs were at high risk of bankruptcy and some did even file, which probably drew investors' attention to this sector. Indeed, the fact that those REITs were at high risk of bankruptcy could have created a strong signal (especially when they filed) to markets participants about the real estate market conditions and therefore led to further pessimism. Thus, we acknowledge that correlated low sentiment across investors is a driving force of contagion. Those empirical results support recent theoretical works by Bacchetta, Tille and van Wincoop (forthcoming) and Bacchetta and van Wincoop (2012).

Taken together, the results from our sentiment channel test suggest that the financial mechanisms underlying contagion are not the unique vectors of contagion. We show that excess return comovements are amplified by panic risk. This result is consistent with the view that behavioral biases are stronger in crisis periods and that irrational investors' decisions do have an impact on financial markets. Thus, we acknowledge that a behavioral dimension in the spirit of the 'noise trader' theories is crucial to consider in order to fully understand the mechanisms of contagion. These findings bring new insights to the sentiment-based comovement theory introduced by Barberis, Shleifer and Wurgler (2005) as this theory is tested in a particular state of the economy.

\subsubsection{Asymmetric Effects}

The purpose of this section is to analyze the role of our significant contagion channels in a framework where markets are dominated by high positive returns. To this end, we look at the excess comovements (filtered returns) that appear in the upper tail distribution of our series. More specifically, we investigate how upper 
tail dependences, stemming from the conditional SJC copula, are linked to funding liquidity, commonality in liquidity and investor sentiment. This analysis allows us to see whether our significant channels are specific to the contagion phenomenon or whether they also have an explanatory power in good market conditions. Moreover, the results of these tests will bring new insights with respect to the asymmetric effects of these factors according to the state of the economy.

$$
\text { [Tables } 10 \text { and } 11 \text { about here] }
$$

The results of the credit availability and commonality in liquidity are displayed in Tables 10 and 11, respectively. Let us first focus on the parameters that were consistent with the financing channel, namely the commercial paper and TED spreads in the pair REITs-S\&P 600. These funding proxies turn out to be significantly negative now, showing opposite effects compared to an environment dominated by market downturns. Thus, credit accessibility tends to lower the linkages between REITs and small cap stocks in a good state of the economy. In this case, funding liquidity is therefore characterized by asymmetric effects on tail dependences. The remaining results do not exhibit any consistent pattern. As for the commonality in liquidity, this variable is no longer significant (in all cases) and has a negative sign for two pairs (i.e., REITs-S\&P 500 and REITs-Banks) in good times. This finding contrasts with the significant effect of commonality in liquidity on the lower tail dependences. Hence, this factor is clearly specific to contagion and as a consequence shows also an asymmetric feature in its effects on tail dependences.

[Table 12 about here]

In the spirit of the sentiment-induced contagion, one could expect that optimism would explain to a some extent return comovements when markets perform well. Hence, we hypothesize a positive relation between sentiment and upper tail dependences. As shown in Table 12 , this hypothesis is verified. Indeed, the sentiment parameter is positive in all cases, which strongly contrasts with the negative relation between sentiment and lower tail dependence. However, none of the coefficients is significant. Thus, investor sentiment is more prevalent for lower tail dependence, which is a clear manifestation of asymmetric effects on comovements. Overall, these findings demonstrate that liquidity and sentiment have asymmetric effects on excess comovements. They also ascertain that these factors are more specific to contagion, which further argues for the relevance of the channels that we have investigated. 


\section{Conclusion}

Recent catastrophic financial market performance at a global scale has raised the interest of investors and policy makers in better understanding the contagion phenomenon. In this paper, we analyze the dynamics of financial contagion within a cross-asset framework (domestic contagion). More precisely, we use the interdependences between the U.S. real estate and equity markets as our testing ground. We seek to answer two questions. First, is there contagion between real estate and financial markets? Second, what are the mechanisms underlying contagion in this context? Both financial and behavioral mechanisms are considered. Addressing those issues is important given the lack of studies in the literature that investigate the contagion channels involving real estate markets.

In the first part of the paper, we test contagion by means of logit regressions by evaluating the joint occurrence of worst returns. The analyses are carried out on the residuals of a multi-factor model that aims to control for common economic risk factors. The results of those tests strongly support the evidence of comovements over and above what might be expected by economic fundamentals.

Given these results, the second part of the paper addresses the question of the contagion channels. Three financial mechanisms, i.e. correlated information, correlated liquidity and portfolio rebalancing, are examined. We also assess behavioral dimensions in contagion by investigating the role played by investor sentiment and panics in explaining excess comovements. Quantile regressions, copulas and time series regressions are utilized for testing these contagion channels. We find some conclusive evidence for the liquidity correlation channel consistent with the theoretical predictions of Brunnermeier and Pedersen (2009). On the other hand, the correlated information and portfolio reallocation hypotheses are strongly rejected as potential mechanisms of contagion. Importantly, we uncover that panic effects are a major factor at play. Indeed, low sentiment significantly increases the risk of contagion. This finding is consistent with the idea that panics help the spreading of crashes across markets. Therefore, this result brings new insights to the sentimentbased comovement theory of Barberis, Shleifer and Wurgler (2005) as we test their theory in a particular state of the economy. A key aspect of these significant factors is that they have asymmetric effects on return comovements. In an analysis of the excess comovements in good market conditions, we find that the liquidity and sentiment variables are more important in explaining lower tail dependences than upper tail dependences. 
Our findings have several policy and practical implications. First, risk management and policies based on standard asset pricing models that ignore the risk of contagion are misleading during stressful periods. Indeed, return comovements are greater than what is implied by economic fundamentals during extreme market conditions and diversification across stocks and real estate is not that useful during such periods. Second, policies that facilitate credit accessibility (especially during a crisis) could avoid or at least mitigate the impacts of contagion. Lenders will be cautious for good reasons but government policy should suggest innovative ways of encouraging lending. Finally, a better understanding of how market frictions and investor sentiment affect comovements and markets in general would lead investors to make more appropriate decisions as regards risk diversification. Also, policies that ignore the psychological factors in stressful times may fail to offset the widespread impact of a crisis. In other words, policies that only try to regulate institutional behavior in order to diminish the impact of a crisis are likely to be sub-optimal. In this respect, a complementary research to ours would be to dig deeper into the mechanisms related to loss aversion and ambiguity aversion that might have amplified contagion, as those factors are likely to be important. 


\section{References}

[1] Allen, F. and D. Gale. 2000. Financial Contagion. Journal of Political Economy 108: 1-33.

[2] Amihud, Y. 2002. Illiquidity and Stock Returns: Cross-Section and Time-Series Effects. Journal of Financial Markets 5: 31-56.

[3] Ang, A., R. Hodrick, Y. Xing and X. Zhang. 2006. The Cross-Section of Volatility and Expected Returns. Journal of Finance 61: 259-299.

[4] Bacchetta, P., C. Tille and E. van Wincoop. Forthcoming. Self-Fulfilling Risk Panics. American Economic Review.

[5] Bacchetta, P. and E. van Wincoop. 2012. Sudden Spikes in Global Risk. mimeo.

[6] Bae, K., G. A. Karolyi and R. M. Stulz. 2003. A New Approach to Measuring Financial Contagion. Review of Financial Studies 16: 717-763.

[7] Baker, M. and J. Wurgler. 2006. Investor Sentiment and the Cross-Section of Stock Returns. Journal of Finance 61: 1645-1680.

[8] Baker, M. and J. Wurgler. 2007. Investor Sentiment in the Stock Market. Journal of Economic Perspectives 21: 129-151.

[9] Barberis, N., A. Shleifer and J. Wurgler. 2005. Comovement. Journal of Financial Economics 75: 283-317.

[10] Boyer, B. H., T. Kumagai and K. Yuan. 2006. How Do Crises Spread? Evidence from Accessible and Inaccessible Stocks Indices. Journal of Finance 61: 9571003.

[11] Boyson, N. M., C. W. Stahel and R. M. Stulz. 2010. Hedge Fund Contagion and Liquidity Shocks. Journal of Finance 65: 1789-1816.

[12] Brown, G. W. and M. T. Cliff. 2007. Investor Sentiment and Asset Valuation. Journal of Business 78: 405-440.

[13] Brunnermeier, M. K. 2009. Deciphering the Liquidity and Credit Crunch 20072008. Journal of Economic Perspectives 23: 77-100.

[14] Brunnermeier, M. K and L. H. Pederden. 2009. Market Liquidity and Funding Liquidity. Review of Financial Studies 22: 2201-2238. 
[15] Choi, N. and R. W. Sias. 2009. Institutional Industry Herding. Journal of Financial Economics 94: 469-491.

[16] Chordia, T., R. Roll and A. Subrahmanyam. 2001. Market Liquidity and Trading Activity. Journal of Finance 56: 501-530.

[17] Chordia, T., A. Sarkar and A. Subrahmanyam. 2005. An Empirical Analysis of Stock and Bond Market Liquidity. Review of Financial Studies 18: 85-129.

[18] Clayton, J., D. C. Ling and A. Naranjo. 2009. Commercial Real Estate Valuation: Fundamentals Versus Investor Sentiment. Journal of Real Estate Finance and Economics 38: 5-37.

[19] De Long, B. J., A. Shleifer, L. H. Summers, and R. J. Waldmann. 1990. Noise Trader Risk in Financial Markets. Journal of Political Economy 98: 703-738.

[20] Dudley, E. and M. Nimalendran. 2011. Margins and Hedge Funds Contagion. Journal of Financial and Quantitative Analysis 46: 1227-1257.

[21] Eichengreen, B., A. Rose and C. Wyplosz. 1996. Contagious Currency Crises: First Tests. Scandinavian Journal of Economics 98: 463-484.

[22] Embrechts, P., A. McNeil and D. Straumann. 2002. Correlation and Dependence in Risk Management: Properties and Pitfalls. In: Risk Management: Value at Risk and Beyond, ed. M.A.H. Dempster, Cambridge: Cambridge University Press, 176-223.

[23] Fama, E. F. and K. French. 1988. Dividend Yields and Expected Stock Returns. Journal of Financial Economics 22: 3-25.

[24] Fama, E. F. and K. French. 1993. Common Risk Factors in the Returns on Stocks and Bonds. Journal of Financial Economics 33: 3-56.

[25] Fry, R., V. L. Martin and C. Tang. 2010. New Class of Tests of Contagion With Applications. Journal of Business and Economic Statistics 28: 423-437.

[26] Gerlach, R., P. Wilson and R. Zurbruegg. 2006. Structural Breaks and Diversification: The Impact of the 1997 Asian Financial Crisis on the Integration of Asia-Pacific Real Estate Markets. Journal of International Money and Finance 25: 974-991. 
[27] Glosten, L. R., R. Jagannathan and D. E. Runkle. 1993. On the Relation Between the Expected Value and the Volatility of the Nominal Excess Return on Stocks. Journal of Finance 48: 1779-1801.

[28] Hoesli M. and E. Oikarinen. 2012. Are REITs Real Estate? Evidence from International Sector Data. Journal of International Money and Finance 31: 1823-1850.

[29] Hoesli, M. and K. Reka. Forthcoming. Volatility Spillovers, Comovements and Contagion in Securitized Real Estate Markets. Journal of Real Estate Finance and Economics.

[30] Joe H. 1997. Multivariate Models and Dependence Concepts. London: Chapman \& Hall.

[31] Kallberg, J. G., C. H. Liu and P. Pasquariello. 2002. Regime Shifts in Asian Equity and Real Estate Markets. Real Estate Economics 30: 263-291.

[32] Kallberg, J. G., C. H. Liu and P. Pasquariello. 2005. An Examination of the Asian Crisis: Regime Shifts in Currency and Equity Markets. Journal of Business 78: 169-211.

[33] Kaminsky, G., C. Reinhardt and C. Végh. 2003. The Unholy Trinity of Financial Contagion. Journal of Economic Perspectives 17: 51-74.

[34] Karolyi, G. A., K. Lee and M. A. van Dijk. Forthcoming. Understanding Commonality in Liquidity around the World. Journal of Financial Economics.

[35] King, M. and S. Wadhwani. 1990. Transmission of Volatility Between Stock Markets. Review of Financial Studies 3: 5-33.

[36] Kiyotaki, N. and J. Moore. 2002. Evil is the Root of all Money. American Economic Review: Papers and Proceedings 85: 62-66.

[37] Kodres, L. E. and M. Pritsker. 2002. A Rational Expectations Model of Financial Contagion. Journal of Finance 57: 769-800.

[38] Koenker, R. 2005. Quantile Regression. Cambridge: Cambridge University Press.

[39] Kumar, A. and C. M. Lee. 2006. Retail Investor Sentiment and Return Comovements. Journal of Finance 61: 2451-2486. 
[40] Kyle, A. S. and W. Xiong. 2001. Contagion as a Wealth Effect. Journal of Finance 56: 1401-1440.

[41] Lemmon, M. and E. Portniaguina. 2006. Consumer Confidence and Asset Prices: Some Empirical Evidence. Review of Financial Studies 19: 1499-1529.

[42] Liew, J. and M. Vassalou. 2000. Can Book-to-Market, Size and Momentum be Risk Factors that Predict Economic Growth? Journal of Financial Economics 57: 221-245.

[43] Ling, D. C., A. Naranjo and B. Scheick. 2012. Credit Availability and Asset Pricing in Illiquid Markets. Working Paper. University of Florida, Gainesville, FL.

[44] Ling, D. C., A. Naranjo and B. Scheick. 2013. Investor Sentiment, Limits to Arbitrage, and Private Market Returns. Real Estate Economics 41, forthcoming.

[45] Longstaff, F. A. 2010. The Subprime Credit Crisis and Contagion in Financial Markets. Journal of Financial Economics 97: 436-450.

[46] Patton, A. J. 2006. Modeling Asymmetric Exchange Rate Dependence. International Economic Review 47: 527-556.

[47] Quigley, J. M. 2001. Real Estate and the Asian Crisis. Journal of Housing Economics 10: 129-161.

[48] Shleifer, A. and R. Vishny. 1997. The Limits of Arbitrage. Journal of Finance 52: $35-55$.

[49] Sklar, A. 1959. Fonctions de Répartition à n Dimensions et Leurs Marges. Publications de l'Institut de Statistique de Paris 8: 229-231.

[50] Subrahmanyam, A. 2007. Liquidity, Return and Order-Flow Linkages Between REITs and the Stock Market. Real Estate Economics 35: 383-408.

[51] Yuan, K. 2005. Asymmetric Price Movements and Borrowing Constraints: A Rational Expectations Equilibrium Model of Crises, Contagion, and Confusion. Journal of Finance 60: 379-411.

[52] Zhou, J. and R. I. Anderson. Forthcoming. An Empirical Investigation of Herding Behavior in the U.S. REIT Market. Journal of Real Estate Finance and Economics. 


\section{List of Tables}

Table 1: Summary Statistics

\begin{tabular}{|c|c|c|c|c|}
\hline Assets: & REITs & S\&P 600 & S\&P 500 & Banks \\
\hline \multicolumn{5}{|c|}{ Panel A: Summary Statistics - Raw Returns } \\
\hline Mean & 0.16 & 0.12 & 0.02 & -0.09 \\
\hline Standard Deviation & 3.53 & 3.24 & 2.74 & 5.14 \\
\hline Skewness & -0.36 & -0.58 & -0.78 & 0.20 \\
\hline Kurtosis & 11.26 & 6.20 & 9.04 & 14.02 \\
\hline \multicolumn{5}{|c|}{ Panel B: Summary Statistics - Liquidity } \\
\hline Mean & 3.07 & 47.59 & 3014.86 & 4040.84 \\
\hline Standard Deviation & 3.91 & 52.51 & 2801.66 & 3812.69 \\
\hline Skewness & 2.43 & 0.89 & 0.66 & 1.28 \\
\hline Kurtosis & 9.74 & 2.63 & 2.27 & 4.72 \\
\hline \multicolumn{5}{|c|}{ Panel C: Simple Correlations - Filtered Returns } \\
\hline REITs & 1.00 & 0.51 & 0.46 & 0.34 \\
\hline S\&P 600 & & 1.00 & 0.92 & 0.59 \\
\hline S\&P 500 & & & 1.00 & 0.61 \\
\hline Banks & & & & 1.00 \\
\hline
\end{tabular}


Table 2: Multi-Factor Model Estimations

\begin{tabular}{|c|c|c|c|c|}
\hline Assets: & REITs & S\&P 600 & S\&P 500 & Banks \\
\hline Constant & $\begin{array}{l}0.026^{* *} \\
(2.455)\end{array}$ & $\begin{array}{l}0.014^{* *} \\
(2.202)\end{array}$ & $\begin{array}{l}0.011^{*} \\
(1.946)\end{array}$ & $\begin{array}{l}-0.010 \\
(-0.798)\end{array}$ \\
\hline$S M B$ & $\begin{array}{l}0.693^{* * *} \\
(5.651)\end{array}$ & $\begin{array}{l}0.962^{* * *} \\
(11.746)\end{array}$ & $\begin{array}{l}-0.004 \\
(-0.004)\end{array}$ & $\begin{array}{l}-0.088 \\
(-0.522)\end{array}$ \\
\hline$H M L$ & $\begin{array}{l}0.668^{* * *} \\
(8.572)\end{array}$ & $\begin{array}{l}0.107 \\
(1.467)\end{array}$ & $\begin{array}{l}-0.169^{* *} \\
(-2.333)\end{array}$ & $\begin{array}{l}0.859^{* * *} \\
(3.680)\end{array}$ \\
\hline$M O M$ & $\begin{array}{l}-0.304^{* * *} \\
(-4.719)\end{array}$ & $\begin{array}{l}-0.205^{* * *} \\
(-3.874)\end{array}$ & $\begin{array}{l}-0.192^{* * *} \\
(-4.187)\end{array}$ & $\begin{array}{l}-0.553^{* * *} \\
(-4.682)\end{array}$ \\
\hline T-bill rate & $\begin{array}{l}-0.129 \\
(-0.773)\end{array}$ & $\begin{array}{l}-0.057 \\
(-0.425)\end{array}$ & $\begin{array}{l}0.019 \\
(0.163)\end{array}$ & $\begin{array}{l}0.355 \\
(1.199)\end{array}$ \\
\hline Credit Spread & $\begin{array}{l}-0.663^{* * *} \\
(-2.840)\end{array}$ & $\begin{array}{l}-0.396^{* * *} \\
(-3.411)\end{array}$ & $\begin{array}{l}-0.396^{* * *} \\
(-3.689)\end{array}$ & $\begin{array}{l}-0.438 \\
(-1.521)\end{array}$ \\
\hline Term Spread & $\begin{array}{l}-0.040 \\
(-0.176)\end{array}$ & $\begin{array}{l}-0.041 \\
(-0.225)\end{array}$ & $\begin{array}{l}0.076 \\
(0.465)\end{array}$ & $\begin{array}{l}0.685 \\
(1.574)\end{array}$ \\
\hline$\Delta V I X$ & $\begin{array}{c}-0.005^{* * *} \\
(-12.698)\end{array}$ & $\begin{array}{l}-0.007^{* * *} \\
(-18.745)\end{array}$ & $\begin{array}{c}-0.007^{* * *} \\
(-19.064)\end{array}$ & $\begin{array}{l}-0.007^{* * *} \\
(-8.195)\end{array}$ \\
\hline Industrial Prod. & $\begin{array}{l}-0.397 \\
(-0.726)\end{array}$ & $\begin{array}{l}0.489 \\
(1.149)\end{array}$ & $\begin{array}{l}0.285 \\
(0.734)\end{array}$ & $\begin{array}{l}1.465^{*} \\
(1.652)\end{array}$ \\
\hline Inflation & $\begin{array}{l}-0.134 \\
(-1.601)\end{array}$ & $\begin{array}{l}-0.050 \\
(-0.866)\end{array}$ & $\begin{array}{l}-0.074 \\
(-1.381)\end{array}$ & $\begin{array}{l}0.050 \\
(0.339)\end{array}$ \\
\hline Dividend Yields & $\begin{array}{l}0.000 \\
(-0.438)\end{array}$ & $\begin{array}{l}0.000 \\
(-0.597)\end{array}$ & $\begin{array}{l}0.000 \\
(-0.078)\end{array}$ & $\begin{array}{l}0.000^{*} \\
(1.735)\end{array}$ \\
\hline$S E N T_{t-1}$ & $\begin{array}{l}0.000 \\
(0.203)\end{array}$ & $\begin{array}{l}0.000 \\
(-0.148)\end{array}$ & $\begin{array}{l}0.000 \\
(-0.870)\end{array}$ & $\begin{array}{l}0.000 \\
(-0.440)\end{array}$ \\
\hline $\operatorname{AR}(1)$ & $\begin{array}{l}-0.060 \\
(-1.323)\end{array}$ & $\begin{array}{l}-0.027 \\
(-1.069)\end{array}$ & $\begin{array}{l}0.025 \\
(0.667)\end{array}$ & $\begin{array}{l}-0.112^{* *} \\
(-2.074)\end{array}$ \\
\hline Adj. $R^{2}$ & 0.516 & 0.716 & 0.672 & 0.506 \\
\hline
\end{tabular}

Table 2 reports the multi-factor model estimates for each asset returns considered in this study as well as the Adjusted- $R^{2}$. The following factors are included in the model: the size $(S M B)$, book-to-market $(H M L)$ and momentum (MOM) factors; the T-bill rate, the credit and term spreads; the variations in VIX, the industrial production growth, the inflation rate and the dividend yields; a sentiment index and an $\operatorname{AR}(1) .{ }^{* * *}, * *$, and $*$ denote significance at the $1 \%, 5 \%$ and $10 \%$ confidence levels, respectively. The Newey-West $t$-statistics are reported in parentheses. The sample period is from January 1, 1999 to September 30, 2011. 
Table 3: Logit Regression Estimations - Contagion Tests

\begin{tabular}{llll}
\hline \hline Assets: & S\&P 600 & S\&P 500 & Banks \\
\hline \multirow{3}{*}{ Constant } & $-2.809^{* * *}$ & $-2.690^{* * *}$ & $-2.609^{* * *}$ \\
& $(-15.900)$ & $(-16.050)$ & $(-16.120)$ \\
\multirow{2}{*}{ REITs } & $2.748^{* * *}$ & $2.385^{* * *}$ & $2.114^{* * *}$ \\
& $(9.068)$ & $(7.944)$ & $(7.025)$ \\
Pseudo $R^{2}$ & 0.180 & 0.133 & 0.101 \\
$\Delta$ Probability & 0.428 & 0.361 & 0.310 \\
& & & \\
\hline
\end{tabular}

Table 3 reports the logit regression estimation results for the contagion tests. The Pseudo $R^{2}$ and the variation of the probability of observing an extreme negative return for an asset given that the other asset has an extreme negative return are also displayed. The filtered returns stemming from the multi-factor model are used in these tests. The variables are modeled as binary variables set to one if the filtered return has a value in the lowest $10 \%$ of its distribution. ${ }^{* * *},{ }^{* *}$, and $*$ denote significance at the $1 \%, 5 \%$ and $10 \%$ confidence levels, respectively. The $t$-statistics are reported in parentheses. The sample period is from January 1, 1999 to September 30, 2011. 
Table 4: Quantile Regression Estimations - Information Channel

\begin{tabular}{|c|c|c|c|c|c|c|}
\hline \multicolumn{7}{|c|}{ Panel A: From REITs to Stocks } \\
\hline \multirow[b]{2}{*}{ Quantiles: } & \multicolumn{2}{|c|}{ S\&P 600} & \multicolumn{2}{|c|}{ S\&P 500} & \multicolumn{2}{|c|}{ Banks } \\
\hline & Q $10 \%$ & Q $50 \%$ & Q $10 \%$ & Q $50 \%$ & Q $10 \%$ & Q $50 \%$ \\
\hline \multirow{2}{*}{$R E I T s_{t-1}$} & 0.033 & -0.003 & 0.044 & 0.024 & 0.048 & -0.008 \\
\hline & $(0.696)$ & $(-0.114)$ & $(1.398)$ & $(0.828)$ & $(0.629)$ & $(-0.226)$ \\
\hline \multirow[t]{3}{*}{ Pseudo $R^{2}$} & 0.543 & 0.463 & 0.506 & 0.421 & 0.404 & 0.242 \\
\hline & \multicolumn{6}{|c|}{ Panel B: From Stocks to REITs } \\
\hline & \multicolumn{2}{|c|}{ REITs } & \multicolumn{2}{|c|}{ REITs } & \multicolumn{2}{|c|}{ REITs } \\
\hline Quantiles: & Q $10 \%$ & Q $50 \%$ & Q $10 \%$ & Q $50 \%$ & Q $10 \%$ & Q $50 \%$ \\
\hline \multirow[t]{2}{*}{$S \& P 600_{t-1}$} & 0.032 & 0.008 & & & & \\
\hline & $(0.390)$ & $(0.152)$ & & & & \\
\hline \multirow[t]{2}{*}{$S \& P 500_{t-1}$} & & & 0.056 & 0.022 & & \\
\hline & & & $(0.759)$ & $(0.500)$ & & \\
\hline \multirow[t]{2}{*}{ Banks $_{t-1}$} & & & & & 0.005 & -0.051 \\
\hline & & & & & $(0.076)$ & $(-1.160)$ \\
\hline Pseudo $R^{2}$ & 0.383 & 0.218 & 0.383 & 0.218 & 0.382 & 0.220 \\
\hline
\end{tabular}

Table 4 displays the quantile regression estimation results for the correlated information channel test. In addition to the factors used in the multi-factor model (except the autoregressive term), the lagged REIT returns are utilized as explanatory variable for the S\&P $600, \mathrm{~S} \& \mathrm{P} 500$, and Banks returns (Panel A). The results for the REIT returns where the lagged stock returns appear as explanatory variables are shown in Panel B. The model is estimated separetely for each proxy for the stock market. The 10th and 50th quantile regression estimates are reported for each specification as well as their respective Pseudo $R^{2}$. The coefficients for the control variables are not reported for economy of space. ***, **, and * denote significance at the $1 \%, 5 \%$ and $10 \%$ confidence levels, respectively. The $t$-statistics based on bootstrapped standard errors are reported in parentheses. The sample period is from January 1, 1999 to September 30, 2011. 
Table 5: Time-Varying Symmetrized Joe-Clayton Copula Estimations (Lower Tail Dependences) - Liquidity Channel (Funding Liquidity)

\begin{tabular}{|c|c|c|c|c|c|c|c|c|c|}
\hline \multirow{2}{*}{$\begin{array}{l}\text { PAIRS: } \\
\text { Funding Liquidity Variables: }\end{array}$} & \multicolumn{3}{|c|}{ REITs - S\&P 600} & \multicolumn{3}{|c|}{ REITs - S\&P 500} & \multicolumn{3}{|c|}{ REITs - Banks } \\
\hline & TEDSP & CPSP & MTGSP & TEDSP & $\underline{\mathrm{CPSP}}$ & MTGSP & TEDSP & CPSP & MTGSP \\
\hline \multirow[t]{2}{*}{ Constant } & $-1.234^{* * *}$ & $-1.117^{* * *}$ & $-1.850 * * *$ & $-2.432^{* * *}$ & -1.833 & $-2.589^{* * *}$ & $7.422^{* * *}$ & -0.383 & -1.075 \\
\hline & $(-4.167)$ & $(-4.168)$ & $(-3.557)$ & $(-3.717)$ & $(-1.103)$ & $(-4.011)$ & $(2.671)$ & $(-0.302)$ & $(-0.495)$ \\
\hline \multirow[t]{2}{*}{$\mathrm{MA}(10)$} & $2.414^{* * *}$ & $1.757^{* *}$ & -1.010 & -2.070 & -1.086 & $-1.908^{*}$ & $-23.012^{* *}$ & -7.322 & -4.503 \\
\hline & $(3.726)$ & $(2.174)$ & $(-1.267)$ & $(-1.019)$ & $(-0.573)$ & $(-1.917)$ & $(-2.576)$ & $(-1.342)$ & $(-0.894)$ \\
\hline \multirow[t]{2}{*}{$\operatorname{AR}(1)$} & $-1.367^{* * *}$ & $-1.299^{* *}$ & $3.348^{* * *}$ & $3.290 * * *$ & -1.185 & $3.236^{* * *}$ & $-4.803^{* * *}$ & $3.285^{*}$ & 2.503 \\
\hline & $(-3.158)$ & $(-1.979)$ & $(6.095)$ & $(5.106)$ & $(-0.874)$ & $(7.719)$ & $(-3.671)$ & $(1.846)$ & $(0.927)$ \\
\hline \multirow[t]{2}{*}{ Funding Liquidity } & $0.996^{* * *}$ & $1.364^{* * *}$ & $-1.221^{* * *}$ & -0.552 & 1.497 & $-1.617^{* * *}$ & 3.413 & -2.093 & -1.662 \\
\hline & $(6.399)$ & $(5.908)$ & $(-2.674)$ & $(-1.097)$ & $(1.477)$ & $(-2.670)$ & $(1.513)$ & $(-1.220)$ & $(-1.015)$ \\
\hline \multirow[t]{2}{*}{$\log (R E I T L I Q)$} & -0.212 & -0.196 & -0.038 & -0.112 & -0.213 & -0.087 & -0.556 & 0.047 & 0.087 \\
\hline & $(-1.540)$ & $(-1.082)$ & $(-0.200)$ & $(-0.449)$ & $(-1.146)$ & $(-0.449)$ & $(-0.323)$ & $(0.113)$ & $(0.428)$ \\
\hline \multirow[t]{2}{*}{$\log ($ Stock LIQ $)$} & $0.204^{* * *}$ & $0.188^{*}$ & 0.078 & 0.142 & 0.228 & 0.158 & $-0.478^{*}$ & -0.062 & -0.008 \\
\hline & $(2.679)$ & $(1.960)$ & $(1.012)$ & $(1.343)$ & $(0.999)$ & $(1.621)$ & $(-1.902)$ & $(-0.631)$ & $(-0.043)$ \\
\hline
\end{tabular}

Table 5 reports the time-varying symmetrized Joe-Clayton copula estimates for the liquidity correlation channel test, where the lower tail dependence between two assets appear as the dependent variable; the results for the upper tail dependence are not reported. Three pairs are considered: REITs-S\&P 600, REITs-S\&P 500, and REITs-Banks. The filtered returns stemming from the asset pricing model with the sentiment variable are used for modeling the lower tail dependences. As explanatory variables, the lagged value of the lower tail parameter, a moving average of the absolute difference between past errors over 10 periods, and funding and asset liquidity $(L I Q)$ related variables are utilized. The model is estimated for three different funding liquidity proxies: Changes in the TED spread (TED $\mathrm{SP}$ ), the difference between the 3-month commercial paper rate and the 3-month t-bill (CP SP), and the difference between the 30-year conventional mortgage rate and the 3-month t-bill (MTG SP). The natural logarithm of the inverse of the Amihud's illiquidity measure is used as a proxy for asset liquidity. $* * *$, **, and $*$ denote significance at the $1 \%, 5 \%$ and $10 \%$ confidence levels, respectively. The $t$-statistics based on asymptotic standard errors are reported in parentheses. The sample period is from January 1, 1999 to September 30, 2011. 
Table 6: Time-Varying Symmetrized Joe-Clayton Copula Estimations (Lower Tail Dependences) - Liquidity Channel (Commonality in Liquidity)

\begin{tabular}{llll}
\hline \hline Pairs: & REITs - S\&P 600 & REITs - S\&P 500 & REITs - Banks \\
\hline \multirow{2}{*}{ Constant } & $-1.791^{* * *}$ & & \\
& $(-12.009)$ & $-1.605^{* * *}$ & $3.218^{*}$ \\
\multirow{2}{*}{$\operatorname{MA}(10)$} & $-0.615^{*}$ & $(-3.689)$ & $(1.666)$ \\
& $(-1.727)$ & -0.785 & $-24.405^{* *}$ \\
$\operatorname{AR}(1)$ & $3.680^{* * *}$ & $(-1.417)$ & $(-2.001)$ \\
& $(12.200)$ & $3.569^{* * *}$ & $-4.861^{* *}$ \\
CL & $1.595^{* *}$ & $(3.687)$ & $(-4.861)$ \\
& $(2.329)$ & -1.638 & $11.703^{* *}$ \\
& & $(-1.473)$ & $(2.518)$ \\
\hline
\end{tabular}

Table 6 reports the time-varying symmetrized Joe-Clayton copula estimates for the liquidity correlation channel test, where the lower tail dependence between two assets appear as the dependent variable; the results for the upper tail dependence are not reported. Three pairs are considered: REITs-S\&P 600, REITs-S\&P 500, and REITs-Banks. The filtered returns stemming from the asset pricing model with the sentiment variable are used for modeling the lower tail dependences. As explanatory variables, the lagged value of the lower tail parameter, a moving average of the absolute difference between past errors over 10 periods, and the commonality in liquidity $(C L)$ are utilized. ***,**, and * denote significance at the $1 \%, 5 \%$ and $10 \%$ confidence levels, respectively. The $t$-statistics based on asymptotic standard errors are reported in parentheses. The sample period is from January 1, 1999 to September 30, 2011. 
Table 7: Time Series Regressions - REITs/Stocks

\begin{tabular}{|c|c|c|c|}
\hline & $\begin{array}{l}\Delta S \& P 600 \\
\text { Volume }_{t}\end{array}$ & $\begin{array}{l}\Delta S \& P 500 \\
\text { Volume }_{t}\end{array}$ & $\begin{array}{l}\Delta \text { Banks } \\
\text { Volume }_{t}\end{array}$ \\
\hline Constant & $\begin{array}{l}-0.009 \\
(-0.227)\end{array}$ & $\begin{array}{l}0.987 \\
(0.570)\end{array}$ & $\begin{array}{l}0.499 \\
(0.278)\end{array}$ \\
\hline$\Delta$ REIT Volume $_{t-1}$ & $\begin{array}{l}0.063 \\
(1.405)\end{array}$ & $\begin{array}{l}0.665 \\
(0.751)\end{array}$ & $\begin{array}{l}-0.583 \\
(-0.485)\end{array}$ \\
\hline$\Delta S \& P 600$ Volume $_{t-1}$ & $\begin{array}{c}-0.977^{* * *} \\
(-26.188)\end{array}$ & $\begin{array}{l}-6.317^{* * *} \\
(-6.955)\end{array}$ & $\begin{array}{l}-7.648^{* * *} \\
(-4.135)\end{array}$ \\
\hline$\Delta S \& P 500$ Volume $_{t-1}$ & $\begin{array}{l}0.099 * * * \\
(15.270)\end{array}$ & $\begin{array}{l}0.331^{* * *} \\
(3.680)\end{array}$ & $\begin{array}{l}1.473^{* * *} \\
(4.461)\end{array}$ \\
\hline$\Delta$ Banks Volume $_{t-1}$ & $\begin{array}{l}-0.004^{* * *} \\
(-3.550)\end{array}$ & $\begin{array}{l}-0.043^{* * *} \\
(-2.609)\end{array}$ & $\begin{array}{l}-0.422^{* * *} \\
(-5.102)\end{array}$ \\
\hline$\Delta T-$ bill rate $e_{t}$ & $\begin{array}{l}0.014^{* *} \\
(2.238)\end{array}$ & $\begin{array}{l}-0.112 \\
(-0.256)\end{array}$ & $\begin{array}{l}-2.407^{* * *} \\
(-3.211)\end{array}$ \\
\hline$\Delta$ Term Spread $_{t}$ & $\begin{array}{l}-0.629 \\
(-0.888)\end{array}$ & $\begin{array}{l}0.807 \\
(0.020)\end{array}$ & $\begin{array}{l}-96.372^{* *} \\
(-2.385)\end{array}$ \\
\hline$\Delta$ Credit Spread $_{t}$ & $\begin{array}{l}-2.773^{* * *} \\
(-4.154)\end{array}$ & $\begin{array}{l}-50.991 \\
(-0.901)\end{array}$ & $\begin{array}{l}-70.590 \\
(-1.163)\end{array}$ \\
\hline IND. (Low REIT Returns $\left.s_{t-1}\right)$ & $\begin{array}{l}0.098 \\
(0.462)\end{array}$ & $\begin{array}{l}-6.141^{*} \\
(-1.926)\end{array}$ & $\begin{array}{l}-12.919 \\
(-1.226)\end{array}$ \\
\hline Winsorized REIT Returns $s_{t-1}$ & $\begin{array}{l}1.151 \\
(0.559)\end{array}$ & $\begin{array}{l}-46.663 \\
(-0.996)\end{array}$ & $\begin{array}{l}-52.470 \\
(-0.365)\end{array}$ \\
\hline Adjusted- $R^{2}$ & 0.970 & 0.320 & 0.722 \\
\hline
\end{tabular}

Table 7 reports the coefficients from the time series regressions that explain the variations in trading volumes (in U.S. dollars) of the S\&P 600, the S\&P 500 and the Bank indices as well as the Adjusted$R^{2}$. The models also include the changes in the T-bill rate, the term spread and the credit spread as well as an indicator variable that takes the value of one when the REIT returns are in the lowest decile of the distribution and its winsorized variable. ${ }^{* * *}, * *$, and ${ }^{*}$ denote significance at the $1 \%, 5 \%$ and $10 \%$ confidence levels, respectively. The Newey-West $t$-statistics are reported in parentheses. The sample period is from January 1, 1999 to September 30, 2011. 
Table 8: Time Series Regressions - Stocks/REITs

\begin{tabular}{|c|c|c|c|}
\hline & \multicolumn{3}{|c|}{$\Delta$ REITs Volume $_{t}$} \\
\hline & Model (1) & Model (2) & Model (3) \\
\hline \multirow[t]{2}{*}{ Constant } & -0.005 & -0.071 & 0.115 \\
\hline & $(-0.048)$ & $(-0.670)$ & $(1.172)$ \\
\hline \multirow{2}{*}{$\Delta$ REIT Volume $_{t-1}$} & $-0.253^{* * *}$ & $-0.254^{* * *}$ & $-0.259^{* * *}$ \\
\hline & $(-4.742)$ & $(-4.798)$ & $(-4.928)$ \\
\hline \multirow[t]{2}{*}{$\Delta S \& P 600$ Volume $_{t-1}$} & $-0.383^{* * *}$ & $-0.383^{* * *}$ & $-0.383^{* * *}$ \\
\hline & $(-3.027)$ & $(-3.031)$ & $(-3.032)$ \\
\hline \multirow[t]{2}{*}{$\Delta S \& P 500$ Volume $_{t-1}$} & $0.066^{* * *}$ & $0.066^{* * *}$ & $0.066^{* * *}$ \\
\hline & $(3.160)$ & $(3.163)$ & $(3.162)$ \\
\hline \multirow[t]{2}{*}{$\Delta$ Banks Volume $_{t-1}$} & $-0.006^{* *}$ & $-0.006^{* *}$ & $-0.006^{* *}$ \\
\hline & $(-2.565)$ & $(-2.597)$ & $(-2.414)$ \\
\hline \multirow[t]{2}{*}{$\Delta T-$ bill rate r $_{t}$} & $-0.105^{* * *}$ & $-0.104^{* * *}$ & $-0.104^{* * *}$ \\
\hline & $(-2.923)$ & $(-2.915)$ & $(-3.002)$ \\
\hline \multirow[t]{2}{*}{$\Delta$ Term Spread $_{t}$} & $-4.910^{* *}$ & $-5.085^{* *}$ & $-4.589 * *$ \\
\hline & $(-2.305)$ & $(-2.370)$ & $(-2.185)$ \\
\hline \multirow[t]{2}{*}{$\Delta$ Credit $_{\text {Spread }}$} & -3.089 & -3.559 & -2.449 \\
\hline & $(-1.283)$ & $(-1.447)$ & $(-1.016)$ \\
\hline \multirow[t]{2}{*}{ IND. (Low $S \& P 600$ Returns $\left._{t-1}\right)$} & 0.051 & & \\
\hline & $(0.121)$ & & \\
\hline \multirow[t]{2}{*}{ Winsorized $S \& P 600$ Returns $_{t-1}$} & -3.007 & & \\
\hline & $(-0.458)$ & & \\
\hline \multirow[t]{2}{*}{ IND. (Low S\&P500 Returns $\left.s_{t-1}\right)$} & & 0.652 & \\
\hline & & (1.401) & \\
\hline \multirow[t]{2}{*}{ Winsorized $S \& P 500$ Returns $s_{t-1}$} & & -1.412 & \\
\hline & & $(-0.169)$ & \\
\hline \multirow[t]{2}{*}{ IND. (Low Banks Returns $s_{t-1}$ ) } & & & $-1.155^{* *}$ \\
\hline & & & $(-2.173)$ \\
\hline \multirow[t]{2}{*}{ Winsorized Banks Returns $s_{t-1}$} & & & -4.081 \\
\hline & & & $(-0.822)$ \\
\hline Adjusted- $R^{2}$ & 0.670 & 0.671 & 0.673 \\
\hline
\end{tabular}

Table 8 reports the coefficients from the the time series regressions that explains the variations in trading volumes (in U.S. dollars) of the REIT index as well as the Adjusted- $R^{2}$. The models also include the changes in the T-bill rate, the term spread and the credit spread as well as an indicator variable that takes the value of one when the returns of a given stock index are in the lowest decile of the distribution and its winsorized variable. One stock indice's returns are used as exogenous variable per model which yields three different specifications. $* * *, * *$, and $*$ denote significance at the $1 \%, 5 \%$ and $10 \%$ confidence levels, respectively. The Newey-West $t$-statistics are reported in parentheses. The sample period is from January 1, 1999 to September 30, 2011. 
Table 9: Time-Varying Symmetrized Joe-Clayton Copula Estimations (Lower Tail Dependences) - Sentiment/Panic Risk Channel

\begin{tabular}{llll}
\hline \hline Pairs: & REITs - S\&P 600 & REITs - S\&P 500 & REITs - Banks \\
\hline \multirow{2}{*}{ Constant } & $-0.944^{* * *}$ & & \\
& $(-4.745)$ & -0.185 & $-1.481^{* *}$ \\
$\mathrm{MA}(10)$ & $1.028^{* * *}$ & $(-0.489)$ & $(-1.994)$ \\
& $(4.446)$ & -2.204 & -4.391 \\
$\mathrm{AR}(1)$ & $-0.340^{*}$ & $(-1.564)$ & $(-0.967)$ \\
& $(-1.795)$ & -0.415 & $3.884^{*}$ \\
Sentiment & $-0.062^{* * *}$ & $(-0.556)$ & $(1.687)$ \\
& $(-3.595)$ & $-0.047^{* *}$ & -0.014 \\
& & $(-2.223)$ & $(-0.233)$ \\
\hline
\end{tabular}

Table 9 reports the time-varying symmetrized Joe-Clayton copula estimates for the sentiment/panic risk channel test, where the lower tail dependence between two assets appears as the dependent variable; the results for the upper tail dependence are not reported. Three pairs are considered: REITs-S\&P 600, REITs-S\&P 500, and REITs-Banks. The filtered returns stemming from the asset pricing model with the sentiment variable are used for modeling the lower tail dependences. As explanatory variables, the lagged value of the lower tail parameter, a moving average of the absolute difference between past errors over 10 periods, and the sentiment. $*^{* *},{ }^{* *}$, and $*$ denote significance at the $1 \%, 5 \%$ and $10 \%$ confidence levels, respectively. The $t$-statistics based on asymptotic standard errors are reported in parentheses. The sample period is from January 1, 1999 to September 30, 2011. 
Table 10: Time-Varying Symmetrized Joe-Clayton Copula Estimations (Upper Tail Dependences) - Liquidity Channel (Funding Liquidity)

\begin{tabular}{|c|c|c|c|c|c|c|c|c|c|}
\hline \multirow{2}{*}{$\begin{array}{l}\text { PAIRS: } \\
\text { Funding Liquidity Variables: }\end{array}$} & \multicolumn{3}{|c|}{ REITs - S\&P 600} & \multicolumn{3}{|c|}{ REITs - S\&P 500} & \multicolumn{3}{|c|}{ REITs - Banks } \\
\hline & TEDSP & CPSP & MTGSP & TEDSP & CPSP & MTGSP & TEDSP & CPSP & MTGSP \\
\hline \multirow[t]{2}{*}{ Constant } & $-1.851^{* * *}$ & $-1.748^{* * *}$ & 0.004 & $-1.558^{* * *}$ & $-1.511^{* * *}$ & $-1.894^{* * *}$ & -1.565 & -1.342 & -1.102 \\
\hline & $(-28.010)$ & $(-14.780)$ & $(0.008)$ & $(-4.368)$ & $(-2.769)$ & $(-3.769)$ & $(-1.641)$ & $(-1.130)$ & $(-0.987)$ \\
\hline \multirow[t]{2}{*}{$\mathrm{MA}(10)$} & $-0.944^{* * *}$ & $-1.132^{* * *}$ & -0.667 & -1.052 & -1.712 & 0.499 & $-3.366^{*}$ & $-3.596^{*}$ & -4.649 \\
\hline & $(-11.623)$ & $(-4.940)$ & $(-0.782)$ & $(-0.549)$ & $(-1.647)$ & $(0.960)$ & $(-1.676)$ & $(-1.874)$ & $(-1.464)$ \\
\hline \multirow[t]{2}{*}{$\operatorname{AR}(1)$} & $4.020^{* * *}$ & $3.877^{* *}$ & $-0.832^{* *}$ & $3.800^{* * *}$ & $3.732^{* * *}$ & $4.319^{* * *}$ & $2.249^{* *}$ & 1.948 & 1.748 \\
\hline & $(31.693)$ & $(19.304)$ & $(-2.122)$ & $(4.499)$ & $(11.425)$ & $(28.653)$ & $(2.098)$ & $(1.573)$ & $(1.358)$ \\
\hline \multirow[t]{2}{*}{ Funding Liquidity } & $-0.512^{* * *}$ & $-0.714^{* * *}$ & $-1.233^{* *}$ & -0.186 & -0.639 & $1.163^{* * *}$ & -0.594 & -0.241 & 0.495 \\
\hline & $(-7.428)$ & $(-2.944)$ & $(-2.053)$ & $(-0.358)$ & $(-1.008)$ & $(3.418)$ & $(-1.296)$ & $(-0.353)$ & $(0.616)$ \\
\hline \multirow[t]{2}{*}{$\log (R E I T L I Q)$} & -0.006 & -0.008 & 0.012 & 0.024 & 0.003 & 0.116 & -0.045 & -0.065 & -0.071 \\
\hline & $(-0.803)$ & $(-0.528)$ & $(0.047)$ & $(0.041)$ & $(0.015)$ & $(0.831)$ & $(-0.251)$ & $(-0.518)$ & $(-0.775)$ \\
\hline \multirow[t]{2}{*}{$\log ($ Stock LIQ $)$} & $0.006^{* *}$ & 0.005 & 0.040 & -0.030 & -0.013 & -0.073 & 0.124 & 0.119 & 0.122 \\
\hline & $(2.236)$ & $(0.513)$ & $(0.071)$ & $(-0.335)$ & $(-0.112)$ & $(-0.689)$ & $(1.078)$ & $(0.730)$ & $(1.062)$ \\
\hline
\end{tabular}

Table 10 reports the time-varying symmetrized Joe-Clayton copula estimates for the liquidity correlation channel test, where the upper tail dependence between two assets appear as the dependent variable; the results for the lower tail dependence are not reported. Three pairs are considered: REITs-S\&P 600, REITs-S\&P 500, and REITs-Banks. The filtered returns stemming from the asset pricing model with the sentiment variable are used for modeling the lower tail dependences. As explanatory variables, the lagged value of the lower tail parameter, a moving average of the absolute difference between past errors over 10 periods, and funding and asset liquidity $(L I Q)$ related variables are utilized. The model is estimated for three different funding liquidity proxies: Changes in the TED spread (TED $\mathrm{SP}$ ), the difference between the 3-month commercial paper rate and the 3-month t-bill (CP SP), and the difference between the 30-year conventional mortgage rate and the 3-month t-bill (MTG SP). The natural logarithm of the inverse of the Amihud's illiquidity measure is used as a proxy for asset liquidity. $* * *$, **, and $*$ denote significance at the $1 \%, 5 \%$ and $10 \%$ confidence levels, respectively. The $t$-statistics based on asymptotic standard errors are reported in parentheses. The sample period is from January 1, 1999 to September 30, 2011. 
Table 11: Time-Varying Symmetrized Joe-Clayton Copula Estimations (Upper Tail Dependences) - Liquidity Channel (Commonality in Liquidity)

\begin{tabular}{llll}
\hline \hline Pairs: & REITs - S\&P 600 & REITs - S\&P 500 & REITs - Banks \\
\hline \multirow{3}{*}{ Constant } & $-1.716^{* * *}$ & & \\
& $(-10.182)$ & $-1.890^{* * *}$ & -0.782 \\
\multirow{2}{*}{$\operatorname{MA}(10)$} & $-0.839^{*}$ & $(-7.307)$ & $(-0.562)$ \\
& $(-1.693)$ & -0.817 & -2.865 \\
$\operatorname{AR}(1)$ & $3.696^{* * *}$ & $(-0.748)$ & $(-0.898)$ \\
& $(15.856)$ & $4.160^{* * *}$ & 2.469 \\
CL & 0.285 & $(16.096)$ & $(1.315)$ \\
& $(1.028)$ & -0.627 & -0.620 \\
& & $(-1.498)$ & $(-0.557)$ \\
\hline
\end{tabular}

Table 11 reports the time-varying symmetrized Joe-Clayton copula estimates for the liquidity correlation channel test, where the upper tail dependence between two assets appear as the dependent variable; the results for the lower tail dependence are not reported. Three pairs are considered: REITs-S\&P 600, REITs-S\&P 500, and REITs-Banks. The filtered returns stemming from the asset pricing model with the sentiment variable are used for modeling the lower tail dependences. As explanatory variables, the lagged value of the lower tail parameter, a moving average of the absolute difference between past errors over 10 periods, and the commonality in liquidity $(C L)$ are utilized. ***,**, and * denote significance at the $1 \%, 5 \%$ and $10 \%$ confidence levels, respectively. The $t$-statistics based on asymptotic standard errors are reported in parentheses. The sample period is from January 1, 1999 to September 30, 2011. 
Table 12: Time-Varying Symmetrized Joe-Clayton Copula Estimations (Upper Tail Dependences) - Sentiment Channel

\begin{tabular}{llll}
\hline Pairs: & REITs - S\&P 600 & REITs - S\&P 500 & REITs - Banks \\
\hline \multirow{2}{*}{ Constant } & $-1.753^{* * *}$ & & \\
& $(-18.204)$ & $(-20.101)$ & -0.457 \\
$\operatorname{MA}(10)$ & $-0.799^{* * *}$ & $-2.013^{* * *}$ & $(-0.528)$ \\
& $(-4.718)$ & $(-8.123)$ & -3.891 \\
AR(1) & $3.763^{* * *}$ & $3.744^{* * *}$ & $(-1.251)$ \\
& $(22.339)$ & $(11.180)$ & $2.091^{* *}$ \\
Sentiment & 0.000 & 0.003 & $(2.449)$ \\
& $(0.214)$ & $(0.613)$ & 0.003 \\
& & & $(0.436)$ \\
\hline
\end{tabular}

Table 12 reports the time-varying symmetrized Joe-Clayton copula estimates for the sentiment channel test, where the upper tail dependence between two assets appears as the dependent variable; the results for the lower tail dependence are not reported. Three pairs are considered: REITs-S\&P 600, REITs-S\&P 500 , and REITs-Banks. The filtered returns stemming from the asset pricing model with the sentiment variable are used for modeling the lower tail dependences. As explanatory variables, the lagged value of the lower tail parameter, a moving average of the absolute difference between past errors over 10 periods, and the sentiment. ${ }^{* * *},{ }^{* *}$, and $*$ denote significance at the $1 \%, 5 \%$ and $10 \%$ confidence levels, respectively. The $t$-statistics based on asymptotic standard errors are reported in parentheses. The sample period is from January 1, 1999 to September 30, 2011. 